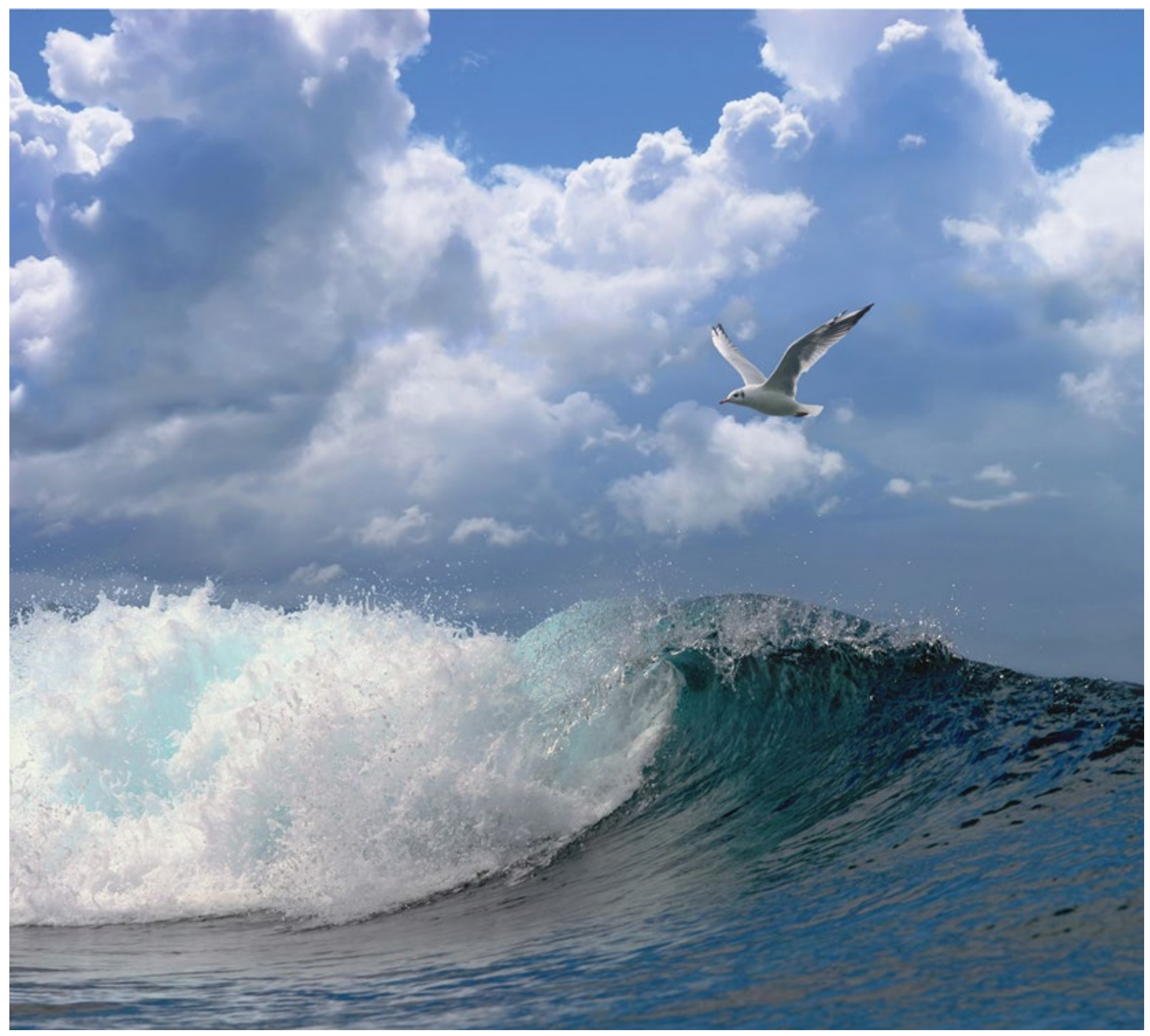

Quantifying harbour porpoise foraging behaviour in CPOD data: identification, automatic detection and potential application 


\section{Quantifying harbour porpoise foraging behaviour in CPOD data: identification, automatic detection and potential application}

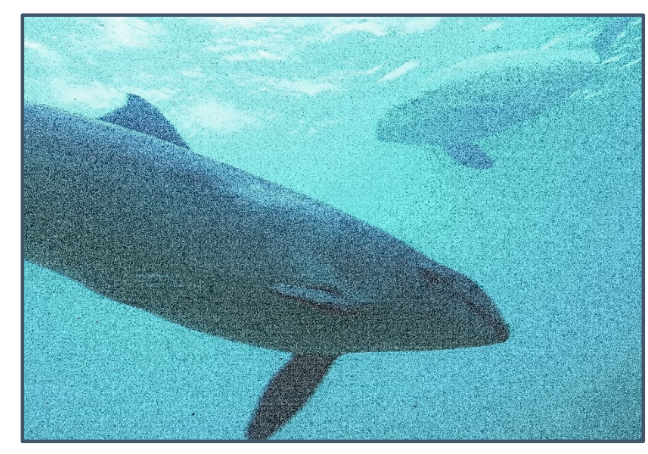

Author(s):

B.J.P. Berges, S.C.V. Geelhoed, M. Scheidat \& J. Tougaard 
Berges, B.J.P., Geelhoed, S.C.V., Scheidat, M., Tougaard, J. 2019. Quantifying harbour porpoise foraging behaviour in CPOD data: identification, automatic detection and potential application. Wageningen, Wageningen Marine Research (University \& Research centre), Wageningen Marine Research report C039/19 Quantifying harbour porpoise foraging behaviour in CPOD data:

identification, automatic detection and potential application, pp. 41

Keywords: Harbour porpoise, Passive Acoustic Monitoring, Offshore wind farm, Foraging Behaviour, Feeding buzz

Date: 21 June 2019

Client:

Aylin Erkman

Verkenning en Planuitwerking Rijkswaterstaat Zee en Delta Poelendaelesingel 18

4335 JA Middelburg

Postbus 556

3000 AN Rotterdam

This report can be downloaded for free from https://doi.org/10.18174/475270 Wageningen Marine Research provides no printed copies of reports

(C) Wageningen Marine Research

Wageningen Marine Research is ISO 9001:2008 certified.

Photo cover: M. Scheidat

(C) Wageningen Marine Research

Wageningen Marine Research, an institute Wageningen Marine Research accepts no liability for consequential damage, nor within the legal entity Stichting for damage resulting from applications of the results of work or other data Wageningen Research (a foundation under obtained from Wageningen Marine Research. Client indemnifies Wageningen Dutch private law) represented by Dr. Marine Research from claims of third parties in connection with this application. M.C.Th. Scholten, Managing Director All rights reserved. No part of this publication may be reproduced and / or

KvK nr. 09098104, published, photocopied or used in any other way without the written permission WMR BTW nr. NL 8113.83.696.B16. of the publisher or author.

Code BIC/SWIFT address: RABONL2U

IBAN code: NL 73 RABO 0373599285 


\section{Contents}

1 Introduction

$2 \quad$ Data overview

2.1 The CPOD

6

2.2 Harbour porpoise foraging behaviour

2.3 Gemini Offshore Wind Farm

2.4 CPOD data collection

3.1 Click train based methods

3.2 Click based methods $\quad 12$

$4 \quad$ Results and discussion $\quad 14$

$\begin{array}{lll}4.1 & \text { Identification of foraging behaviour } & 14\end{array}$

4.1.1 Click train based methodology $\quad 14$

4.1.2 Click based methodology 18

4.2 Methods for automated detection of foraging/feeding events 20

$\begin{array}{lll}\text { 4.2.1 Methodology comparison } & 20\end{array}$

4.2.2 Buzz clicks detection algorithm $\quad 22$

4.3 Application to Gemini data 23

4.3.1 Changes over time and between stations 23

4.3.2 Relation to pile driving activities $\quad 23$

$\begin{array}{lll}4.4 & \text { Limitations } & 24\end{array}$

$\begin{array}{llr}5 & \text { Conclusions and recommendations } & 27\end{array}$

$\begin{array}{llr}5.1 & \text { Conclusions } & 27\end{array}$

$\begin{array}{lll}5.2 & \text { Recommendations } & 28\end{array}$

$\begin{array}{llr}6 & \text { Acknowledgments } & 29\end{array}$

$\begin{array}{llr}7 & \text { Quality Assurance } & \mathbf{3 0}\end{array}$

$\begin{array}{lr}\text { References } & 31\end{array}$

$\begin{array}{lr}\text { Annex I: additional results } & 33\end{array}$

$\begin{array}{lr}\text { Justification } & \mathbf{4 0}\end{array}$ 


\section{Summary}

Harbour porpoises (Phocoena phocoena) are regularly monitored to assess how they are impacted by the construction and operation of offshore wind farms. A suitable method to do this is passive acoustic monitoring (PAM), and in particular using specific stationary hydrophones called CPODs. These devices provide information on click activity, which can then be analysed to investigate habitat use over time, differences between areas and the impact of human activities.

Due to their small size and high metabolism porpoises are thought to need a more or less constant supply of prey to survive. Prey occurrence is thus considered one of the main drivers in porpoise distribution. And successful feeding is vital to the fitness and survival of individual porpoises. Information on foraging behaviour, however, is difficult to obtain in the field, in particular as animals feed under water. Recently the tagging of animals has provided new insights into porpoise behaviour, but it has been done for a limited number of individuals and for short times only.

CPOD data have been used in Dutch waters to monitor harbour porpoise habitat use and behaviour before, during and after the construction of wind farms. The analyses have focussed on using a number of parameters that can be derived from the data, such as porpoise positive minutes, hours or days, encounter and waiting times. From other studies, primarily in captivity, we know that during foraging porpoises produce a characteristic pattern of clicks, starting with an approach phase and ending with a so-called "terminal buzz". Aim of our study was to investigate if we could quantify foraging behaviour from CPOD data, and we were able to use an existing data set of harbour porpoise click activity from the Gemini wind park (June 2015 to February 2016).

The study consisted of three phases. First, the different existing methods were applied to a sample set of data to determine the most suitable approach to identify foraging behaviour. The results indicate that re-classification of clicks following the method developed by Pirotta $(2014 a, b)$ to identify terminal buzzes provides the best results. Second, an algorithm was written to allow the automated analyses of CPOD data following this method. Finally, this analytical tool was applied to the Gemini wind park data to explore the potential applications of this method. The results show that foraging events could be determined in sufficient numbers to detect patterns over time, such as diel patterns, as well as to compare differences between stations.

We propose that this tool is applied to a larger dataset to investigate: 1 ) how porpoises use existing wind parks during the operational phase, 2) if and at what scale anthropogenic activities (such as construction work) impact foraging behaviour and 3) how foraging behaviour is linked to environmental parameters, including prey occurrence.

This study was funded through the WOZEP project and the data were provided by Gemini Windpark. 
The conservation of the most abundant marine mammal in Dutch waters, the harbour porpoise (Phocoena phocoena), is an obligation under different European legislation and agreements, such as the Habitats Directive, the Marine Strategy Framework Directive and ASCOBANS. It is also highlighted in the Dutch Harbour Porpoise Conservation Plan (Bruinvisbeschermingsplan) (Camphuysen \& Siemensma, 2011).

A number of human activities are known to be potentially detrimental to harbour porpoise. Some of these can be fatal (such as bycatch) or cause injury, others can lead to a change in behaviour. One example of the latter is that emission of high energy sound, as it occurs during offshore wind park construction, can lead to displacement of animals away from the sound source (e.g. Brandt et al., 2014). If the area where animals were present initially was an important feeding area, this movement might lead to reduced feeding opportunities. Depending on how often this type of disturbance occurs, it could in turn potentially influence the long-term fitness and survival of the animal.

Having a large body surface to volume ratio and high metabolism, the harbour porpoise needs a constant supply of high energy prey to meet its high energy requirements (Kastelein, 1998; Leopold, 2015; Wisniewska et al., 2016). The general assumption right now is that a reduction in feeding could have a negative impact on porpoise survival. Some limited data on feeding budgets is available from animals held in captivity (Kastelein et al., 1997, 2019), as well as from recent tagging results (Wisniewska et al., 2016). However, on what scale feeding activities might be disrupted due to human activity is still unclear. Currently a number of research groups are working on models that allow this type of individual reaction of porpoises to be translated to the impact on a population level (Harwood et al., 2016; NabeNielsen \& Harwood, 2016; Nabe-Nielsen et al., 2014). However, to this date the input information for the model is based primarily on expert opinion, and has not been quantified.

This study investigates the possibility to obtain a measure of foraging activity through the analysis of acoustic data from porpoise vocalisations. As feeding success is the main parameter impacting porpoise fitness, and a direct link between human activity and changes in foraging behaviour would allow a more accurate interpretation on the actual impact of human activities on harbour porpoise populations. This understanding is vital to develop adequate conservation and management actions.

Observing behaviour of harbour porpoise in the wild is notoriously difficult due to its small size and inconspicuous behaviour. Visual observations are limited to daylight hours and good weather conditions. Passive acoustic monitoring (PAM) has become a standard method to investigate harbour porpoise echolocation activity and changes thereof. Currently most datasets that are collected in the context of wind farm construction and wind farm operation are collected using PAM methods. The information obtained from stationary hydrophones is generally analysed with respect to changes in acoustic activity, such as detection positive minutes within an hour, as a proxy for occurrence of harbour porpoise. When PAM devices are positioned at different distances to a sound source (e.g. pile driving during construction of wind farm) the change in acoustic activity can allow conclusions on the range at which the animals show avoidance behaviour. What the data so far could not provide is if and how foraging behaviour might be impacted.

The aim of this study is to: 1 ) investigate if it is possible to identify foraging behaviour of porpoises from existing PAM data sets and select the most suitable approach 2) develop and apply an algorithm for the automatic identification of foraging events and 3) apply this to an existing dataset from the Gemini offshore wind farm to assess the potential applications of the method.

This report provides a comparison of different analysis approaches to obtain insight in the feasibility of the methods to describe feeding behaviour. The report is neither intended to analyse foraging behaviour patterns, nor potential effects of pile driving activities in the Gemini offshore wind farm. 


\section{Data overview}

In this chapter we describe the information relevant for the analyses conducted for this report. For a more in-depth description of the data and the method of data collection in the field we would like to refer the reader to Geelhoed et al. (2018).

\subsection{The CPOD}

The CPOD or Continuous POrpoise Detector is a self-contained stationary passive acoustic monitoring device. It is aimed at monitoring toothed whales by means of identifying their specific use of highfrequency sounds (echolocation), covering a frequency range of 20-160 kHz with a detection threshold of around $110-115 \mathrm{~dB}$ peak-to-peak re $1 \mu \mathrm{Pa}$ at $130 \mathrm{kHz}$ and a $5-\mu$ s resolution. The CPOD manufacturer (Chelonia Ltd, 2012) provides a completely integrated product (from hardware to processing solutions).

In practice, the CPOD unit works as a click detector. The CPOD device does not record the actual time signals of the clicks, but derives a set of descriptive parameters based on time information derived from measurements of timing of zero crossings in the signal. Though efficient for the recording of signals such as Narrow Band High Frequency (NBHF) signals, it is important to note that zeros crossing measurements are different from the actual measurement of the acoustic pressure using hydrophones. The later resolves the signal between the zero crossing intervals (given a high enough sampling frequency) and results in a much higher volume of data stored. The filtering reduces the data volume and enables CPODs to autonomously collect data for several months before batteries need to be changed and data downloaded. This is considerably longer than the (current) monitoring period possible for PAM devices like the $\mathrm{SM} \mathrm{M}^{1}$ or the soundtrap ${ }^{2}$, which can collect full recording for several weeks. These are able to store the raw acoustic pressure at a given sampling frequency, whereas the CPOD only records the timing of clicks and thus loses significant amounts of information present in the full signal.

The CPOD is particularly powerful in detecting echolocation signals from porpoises as it relies on the stereotypical NBHF nature of these signals (Clausen et al., 2011; Miller, 2010). These are distinctive in lasting about 50-150 microseconds, and containing virtually no energy below $100 \mathrm{kHz}$. The main part of the energy is in a narrow band between $120-150 \mathrm{kHz}$, peaking at around $132 \mathrm{kHz}$, which makes the signals ideal for automatic detection. Other cetacean species such as bottlenose dolphins also produce clicks that can be efficiently recorded by CPODs (Sostres Alonso \& Nuuttila 2015). However, dolphins can be easily distinguished from harbour porpoises as they typically use pulses over a more broadband frequency range of 30-150 kHz (Simon et al. 2010, Wahlbert et al. 2011). Most other sounds in the sea, except some boat sonars, are more broadband or have more energy at lower frequencies. Although many non-porpoise clicks are also recorded, these, as well as boat sonars and echo-sounders, are filtered out during post-processing, by analysing the time intervals between successive clicks.

The sensitivity of the CPODs was standardized by the manufacturer before shipping to IMARES/Wageningen Marine Research (WMR). Calibration of the devices was undertaken by the National Physical Laboratory (NPL) in the United Kingdom and rechecked twice in the accredited German Meeresmuseum in Stralsund on 7 August 2015 and 7 December 2015.

\footnotetext{
${ }^{1}$ https://www.wildlifeacoustics.com/products/song-meter-sm3m-submersible

${ }^{2}$ http://www.oceaninstruments.co.nz/soundtrap-300/
} 


\subsection{Harbour porpoise foraging behaviour}

Harbour porpoise have developed a sophisticated sonar system and use echolocation to aid them in orientation, communication and foraging. They emit NBHF clicks. The varying click interval between clicks may be used to distinguish different (acoustic) behaviour (e.g. Koschinski et al., 2008; Miller, 2010; Sørensen et al., 2018; Verfuss et al., 2009). Time series of inter click intervals (ICI) typical of foraging is shown in Figure 1. After a stable click interval of 50-60ms (the initial part of the approach phase), the porpoise starts to decrease the click interval progressively (Miller, 2010). When a porpoise closes in on its prey, the ICI drops sharply from roughly 50ms to below $20 \mathrm{~ms}$. Within the last 1 metre from the prey, the click train ends with a "buzz", with a click interval below $2 \mathrm{~ms}$, indicating prey capture (Carlström, 2005; Miller, 2010; Nurminem, 2010; Verfuss et al., 2009).

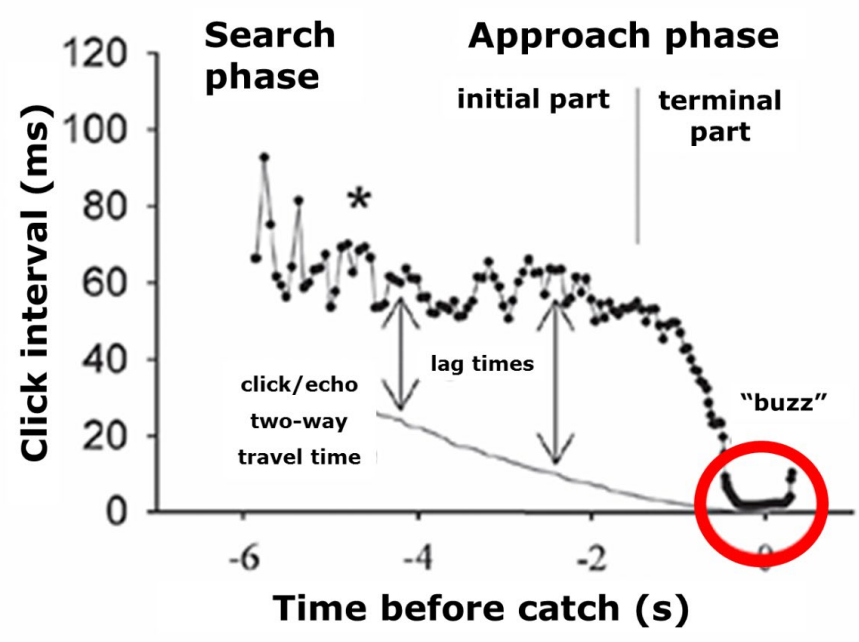

Figure 1: ICI time series typical of harbour porpoises foraging. This includes a search phase, an approach phase and a feeding phase. For each graph, the red circle shows the final feeding "buzz" (ICI upsweep). Full time series from a foraging event, extracted and adapted from Miller, 2010.

\subsection{Gemini Offshore Wind Farm}

The Gemini Offshore Wind Farm (OWF) is designed to produce $600 \mathrm{MW}$ using 150 turbines. It is located $55 \mathrm{~km}$ north of the island of Schiermonnikoog in the southern North Sea (see figure 2). Gemini consists of two sites both $34 \mathrm{~km}^{2}$ in size, Buitengaats $\left(54.04^{\circ} \mathrm{N}, 6.04^{\circ} \mathrm{E}\right)$ and ZeeEnergie $\left(54.03^{\circ} \mathrm{N}, 5.89^{\circ} \mathrm{E}\right.$ (Figure 2). The construction for the monopile foundations for the turbines plus eight piles for the foundations of the two offshore high voltage stations (OHVSs) took place from July 1st until October 18th 2015. Installation of Wind Turbine Generators (WTG's) started in February 2016, while full energy production started in October 2016.

\subsection{CPOD data collection}

A total of fifteen CPODs were deployed in a design spreading $40 \mathrm{~km}$ to the west and $15 \mathrm{~km}$ to the south of the centre of the wind farm site (Figure 2). During the construction phase (T-c), between June 2015 and February 2016, 2228 days of CPOD recordings were obtained. A pool of 30 CPODs was used, out of which 15 were in the water simultaneously. The CPOD locations were serviced three times (29th September, $3^{\text {rd }} \& 27^{\text {th }}$ Oct 2015$)$. CPODs at each location were replaced with new CPOD units, and all equipment was recovered in December 2015 and February 2016. When recovered, CPODs were replaced with new units but using the same memory cards (therefore downloading data prior to deployment). 
The mooring used for the CPODs was similar to the moorings used previously in Dutch studies (Brasseur et al., 2010), in which CPODs are secured with a mooring of two large buoys. The CPOD floats approximately $1 \mathrm{~m}$ above the sea bed.

Regular piling noise occurred during the construction phase of the offshore wind farm (eastern and western parks). The period over which piling activity was conducted lasted between $30^{\text {th }}$ June 2015 and $18^{\text {th }}$ October 2015. Figures related to the piling activity are given in Annex I. The timing of pile driving activity is given in Figure I.1. The intensity of the pile driving was monitored and is shown in Figure I. 2 as cumulative energy per day.

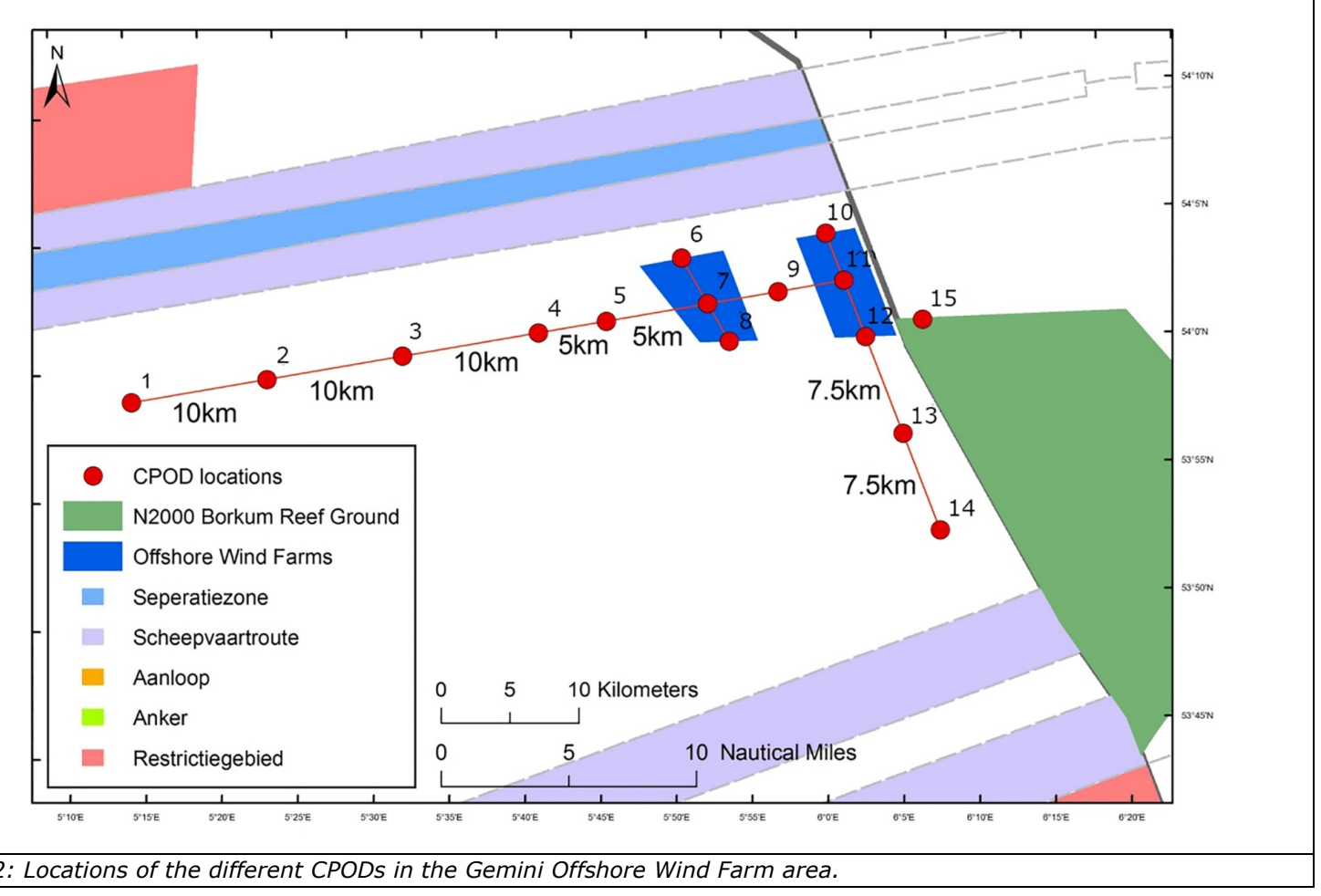

Table 1: Description of CPOD stations which provided the data for the analysis shown in this report. The associated map with the position of the different stations is shown in Figure 2

\begin{tabular}{|c|c|c|c|c|c|}
\hline CPOD ID & Description & $\begin{array}{l}\text { Lat } \\
\text { (N) }\end{array}$ & $\begin{array}{l}\text { Lon } \\
\text { (E) }\end{array}$ & Start time & End time \\
\hline GEM 01 & $40 \mathrm{~km}$ west of Gemini & 53.98 & 5.247 & $30 / 06 / 2015$ & $22 / 12 / 2015$ \\
\hline GEM 02 & $30 \mathrm{~km}$ west of ZeeEnergie & 53.99 & 5.398 & $30 / 06 / 2015$ & $31 / 12 / 2015$ \\
\hline GEM 05 & $5 \mathrm{~km}$ west of Gemini & 54.02 & 5.776 & $25 / 06 / 2015$ & $17 / 11 / 2015$ \\
\hline GEM 06 & ZeeEnergie North & 54.06 & 5.862 & $25 / 06 / 2015$ & 29/12/2015 \\
\hline GEM 07 & ZeeEnergie centre & 54.03 & 5.889 & $23 / 06 / 2015$ & $14 / 12 / 2015$ \\
\hline GEM 08 & ZeeEnergie South & 54.01 & 5.911 & $23 / 06 / 2015$ & $16 / 02 / 2016$ \\
\hline GEM 09 & between ZeeEnergie and Buitengaats & 54.04 & 5.968 & $25 / 06 / 2015$ & $06 / 01 / 2016$ \\
\hline GEM 10 & Buitengaats North & 54.07 & 6.023 & $01 / 07 / 2015$ & $15 / 02 / 2016$ \\
\hline GEM 11 & Buitengaats & 54.04 & 6.041 & $01 / 07 / 2015$ & $26 / 12 / 2015$ \\
\hline GEM 12 & Buitengaats South & 54.01 & 6.063 & 01/07/2015 & $14 / 12 / 2015$ \\
\hline GEM 13 & $7.5 \mathrm{~km}$ south of Buitengaats & 53.94 & 6.099 & $01 / 07 / 2015$ & $14 / 12 / 2015$ \\
\hline GEM 14 & $15 \mathrm{~km}$ south of Buitengaats & 53.88 & 6.136 & $01 / 07 / 2015$ & $14 / 12 / 2015$ \\
\hline GEM 15 & Outside Buitengaats & 54.01 & 6.126 & $25 / 06 / 2015$ & $04 / 12 / 2015$ \\
\hline
\end{tabular}




\section{Method}

In this project, two approaches are used for the detection of foraging events of harbour porpoises:

- Use of entire click trains to identify ICI time series typical of foraging events (click train based approach).

- Use of individual clicks and subsequent potential ICIs that are associated with foraging events (click based approach).

The data used are those recorded at 13 CPODs stations. Data from CPOD stations GEM 03 and GEM 04 are not used since these had less than hundred days of data. Table 1 provides an overview of the position and the time of data collection for the 13 CPOD stations analysed in this study. Recordings from each CPOD station are processed separately.

The CPOD triggers recording for an entire minute at every time a click is detected. Raw data are stored as *.CP1 files and contain all the detected clicks within each minute together with temperature, and tilt of the CPOD. The raw data need to be further processed for filtering and in order to aggregate the clicks into trains. This is done using the "CPOD.exe" software version 2.024 (KERNO classifier). The output of this processing is a *.CP3 file associated to the *.CP1 file. An example of data contained in *.CP3 files is shown in Figure 3.

Table 2: Description of what is contained within a *.CP3 file and extracted using a MATLAB routine. The associated screenshot of the MATLAB workspace after loading a *.CP3 file is shown in Figure 3.

\begin{tabular}{|c|c|c|}
\hline Field name in file & Data description & Field description \\
\hline ID & Integer & ID for the detected train \\
\hline spclass & Integer & $\begin{array}{l}\text { Integer descriptor of the type of the } \\
\text { detected train signal }\end{array}$ \\
\hline species & String (e.g. "Sonar", "NBHF") & $\begin{array}{l}\text { Descriptor of the type of detected } \\
\text { train signal }\end{array}$ \\
\hline qualityclass & Integer & $\begin{array}{l}\text { Integer descriptor of the detection } \\
\text { confidence of the associated train } \\
\text { signal }\end{array}$ \\
\hline quality & String ("Low", "Med", "High") & $\begin{array}{l}\text { Descriptor of the detection } \\
\text { confidence of the associated train } \\
\text { signal }\end{array}$ \\
\hline rategood & Boolean & Use unknown \\
\hline speciesgood & Boolean & Use unknown \\
\hline no_of_clicks & Integer & Number of clicks in train \\
\hline minutes & Serial date number & Start time of click train \\
\hline time & Vector of numbers & $\begin{array}{l}\text { Timing of individual clicks in } \mu s \\
\text { from start time (minute field). }\end{array}$ \\
\hline ici & Vector of numbers & Inter click intervals in $\mu \mathrm{s}$ \\
\hline cycles & Vector of integers & Cycles in clicks \\
\hline nix & Vector of numbers & $\begin{array}{l}\text { peak amplitude, uncalibrated unit } \\
\text { (Nix-unit) }\end{array}$ \\
\hline frq & Vector of numbers & $\begin{array}{l}\text { mean instantaneous frequency in } \\
\mathrm{kHz}\end{array}$ \\
\hline BW & Vector of numbers & $\begin{array}{l}\text { Variation in instantaneous } \\
\text { frequency in } \mathrm{kHz}\end{array}$ \\
\hline fend & Vector of numbers & $\begin{array}{l}\text { Instantaneous frequency at end of } \\
\text { click }\end{array}$ \\
\hline
\end{tabular}




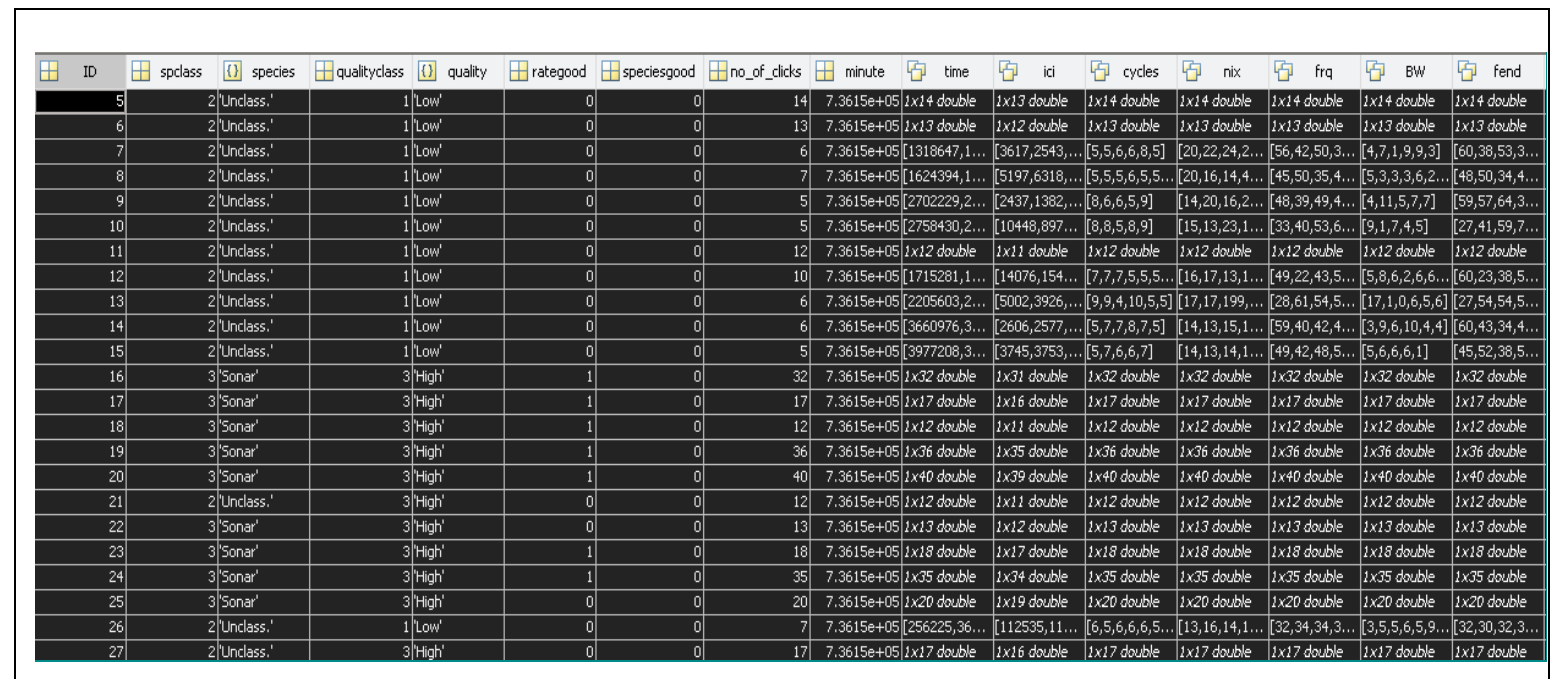

Figure 3: Example of what is contained within a *.CP3 file and extracted using a MATLAB routine. Each row is a detected train with its associated overall information for the train (Table 2)..

From the *.CP3 files, data are further reduced to trains classified as NBHF, i.e. those corresponding to signals from harbour porpoises. The click train quality classification (Table 2, three classes: ("Low", "Medium", "High") is an internal process of the KERNO classifier embedded in the "CPOD.exe. There is no information available on the design of these three filters from the manufacturer, but from the C-POD manual it is known that they reflect the likelihood that the click trains are from porpoises (Sarnocinska et al., 2016). While only selecting the "high" quality click trains is restrictive, trains classified in the "low" quality class likely includes false positives (Sarnocinska et al., 2016). Here, only click trains with a "medium" and "high" quality are retained. The effect of including the click trains classified as "low" is not assessed in this study. This selection of click trains forms the base for the further processing described in the next sections.

\subsection{Click train based methods}

In this section, a methodology for the detection of foraging events by means of characterizing the entire foraging ICI time series is described. As shown in Figure 4 (a) and (b), the ICI time series of a foraging event is characterised by high ICIs ( $>40 \mathrm{~ms}$, i.c. approach phase) followed by a sharp decrease to low ICIs (< $20 \mathrm{~ms}$, i.c. during the catch attempt phase) and eventually a final or terminal "buzz" (ICI upsweep). The method described here fits a simple logistic function describing the trends of ICI time series typical of foraging events.

Click trains are first extracted from the *.CP3 files (contain the classification from the "CPOD.exe" software of individual click train) and filtered based on their signal types and detection qualities. The results of this classification often consists of individual click trains that are part of a larger click train. Because no information on the detection algorithms implemented in the "CPOD.exe" software, one is unable to explain why apparently long click trains are separated in small click trains. This is exemplified in Figure 4(a). What appears to be an entire click train is broken down into five different click trains by the "CPOD.exe" software. For this reason, the click trains initially detected by the "CPOD.exe" software are further regrouped using a 1 second threshold (i.e. regrouping trains that are 1 second or less apart). For example, this allows the click trains shown in Figure 4(a) to be regrouped into a single click train (Figure 4(b)). Though further criteria can be used for the regrouping of the click trains, a conservative approach is used in this study. Though the use of different methods for rearranging click trains have an effect on the fit of the logistic function (method explained below), this is not assessed in this study. 


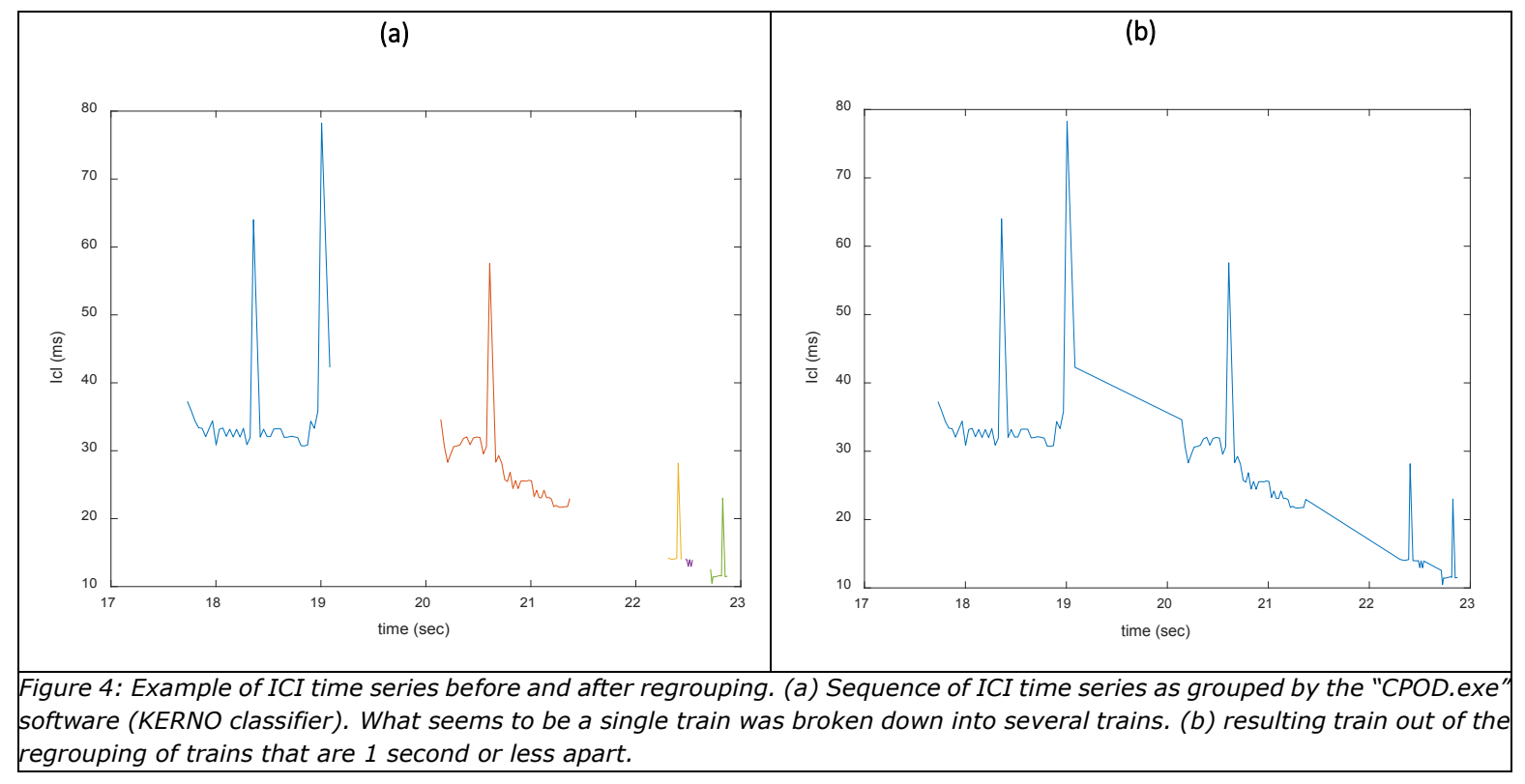

The regrouped click trains are further filtered to those that do not fit the following criteria: (1) having at least one ICI below $15 \mathrm{~ms}$, (2) having at least one ICI above $20 \mathrm{~ms}$. These threshold values are inferred from literature (Miller 2010, Schaffeld et al. 2016). This filters out click trains that most likely do not correspond to a completely resolved foraging event. The effect of this filtering was not quantitively assessed. For each remaining click train, the parameters for the following logistic function (sigmoid) are being estimated:

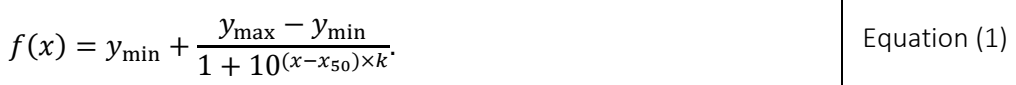

In this equation, $y_{\min }$ and $y_{\max }$ are the minimum and maximum levels of the logistic function respectively, $k$ the steepness of the curve and $x_{50}$ is the $\mathrm{x}$ value of the sigmoid mid-point. Figure 5 shows an schematic sigmoid function together with the different parameters parametrizing it. For each click train that was previously selected, a set of four parameters is estimated and associated. These estimations are used to select the click trains that fit the following conditions:

- $\quad$ End level below $15 \mathrm{~ms}: y_{\min }<15 \mathrm{~ms}$

- $\quad$ Start level above $20 \mathrm{~ms}: y_{\max }>20 \mathrm{~ms}$

- mid-point between $20 \mathrm{~ms}$ and $80 \mathrm{~ms}$ of the starting time of the click train: $20 \mathrm{~ms}<x_{50}<80 \mathrm{~ms}$

- $\quad$ positive slope: $k>0$

The values for these conditions are based on ICI time series observed and reported in the literature (e.g. Miller 2010). 


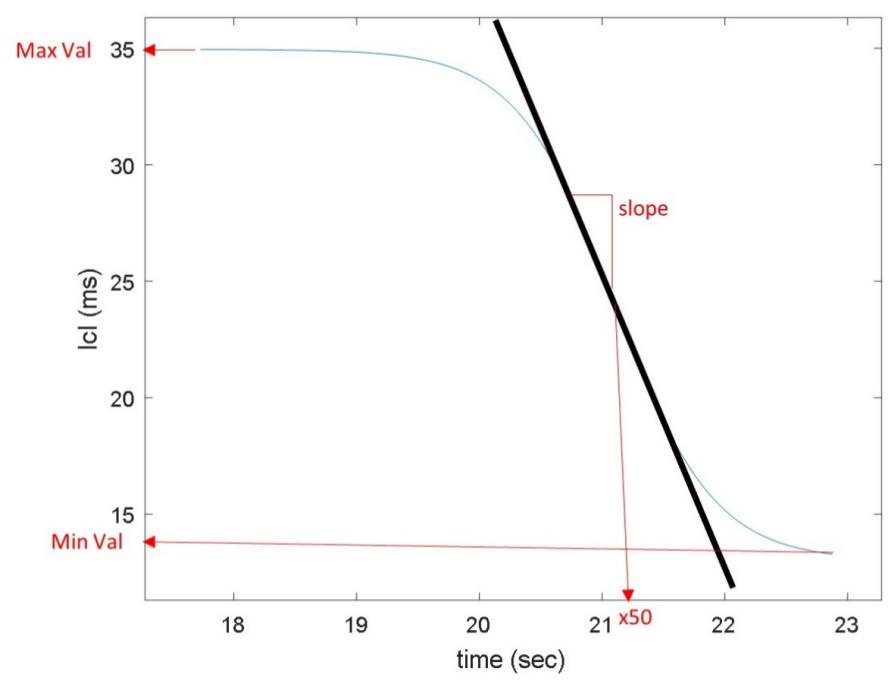

Figure 5: Schematic of the logistic function used to describe foraging events. The logistic function is parametrized using four parameters (see Equation Equation (1)).

\subsection{Click based methods}

In this section, a method to detect clicks that are potentially related to foraging is described. In literature foraging, more specifically feeding behaviour has been associated with buzzes consisting of ICIs below 10ms (e.g. Carlström, 2005; Leeney et al., 2011; Miller, 2010; Nurminem, 2010; Todd et al., 2009; Verfuss et al., 2009). We followed the approach by Pirotta et al. (2014a,b) in which an ICI of less than $10 \mathrm{~ms}$ is used to classify and quantify buzzes associated with foraging behaviour.

First, every click train in the *.CP3 files is separated into individual clicks. Then, each ICI is calculated. The ICI from all the recordings is used to form a log ICI distribution. A three components Gaussian mixture model is then fitted to determine the following groupings of ICI:

- regular ICIs (regular clicking for navigation or prey searching)

- buzz ICI (prey capture or social communication, Clausen et al., 2011, Sørensen et al., 2018)

- $\quad$ inter-train ICI (i.e. pauses between click trains)

Though not used here, it is important to note that it is sometimes necessary to use a four component distribution in case there is a large proportion of regular ICIs compared to buzz ICIs. This is exemplified in Figure 6.

The resulting components of the Gaussian distribution are then used to cluster the different ICIs into the different categories (agglomerative hierarchical cluster tree). Those corresponding to buzz ICIs are retained. 


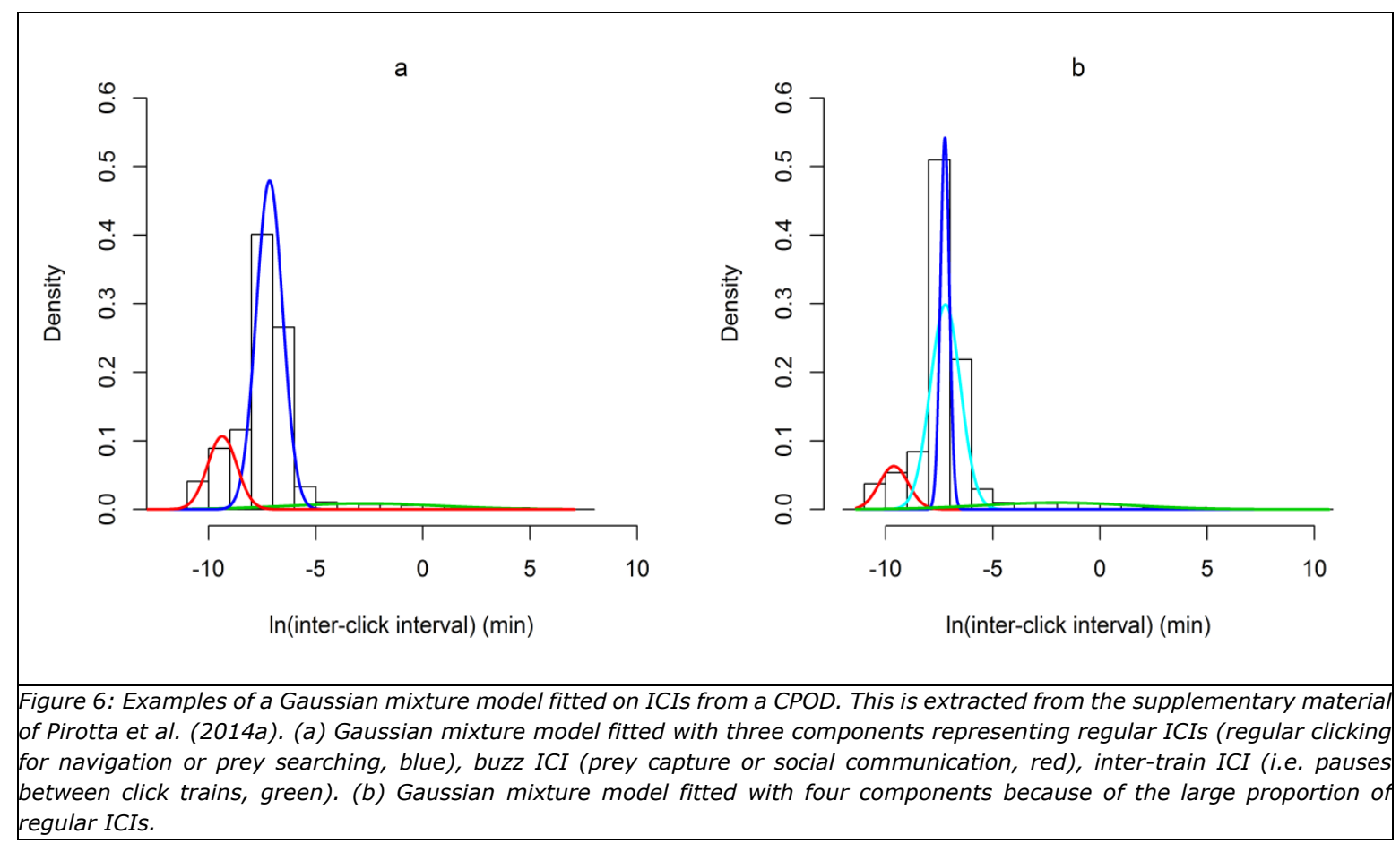


In the following sections we will present the results of the three steps of the analyses process: identification of foraging behaviour, automatic detection and application to the database. The discussion of the results is incorporated in each section.

\subsection{Identification of foraging behaviour}

\subsubsection{Click train based methodology}

This section present the results obtained using the click train based approach (Section 3.1). In short, data from each CPOD is first processed using the "CPOD.exe" software. This is done using the KERNO classifier which effectively filters the raw detected clicks to only those belonging to a click train. For example, the classification is based on parameters of the individual clicks and patterns in the inter-click interval (Sarnocinska et al., 2016). It is important to note that the functioning of the KERNO algorithm is not clearly stated in the CPOD documentation and literature. It is therefore not possible to assess its performance on the data set analysed here. Though of interest, the development and assessment of new methods to classify clicks from raw CPOD data is beyond the scope of this project. As a result, following common practice in the use of CPOD data, the output of the KERNO classifier is used here for analysis. In this section, the results from the analysis of click trains (grouping of clicks) will be presented. More specifically, one uses:

- The initial grouping from the KERNO classifier from the "CPOD.exe" software

- A regrouping of the clicks initially classified using the KERNO classifier. Specifically, the clicks are defined as trains using a 1 second threshold (i.e. regrouping trains that are 1 second or less apart).

The latter is performed because the KERNO classifier sometimes is breaking down a click train into several individual click trains. This makes identifying foraging events more difficult, because a foraging event consists of several phases (see Figure 1) which can be identified through the time series of interclick intervals. It is therefore desirable to have inter-click interval time series representative of the different phases. However, the click train classification using the KERNO classifier tends to break click trains into small chunks and is therefore impractical when identifying foraging events. Figure 4(a) shows an ICI time series example where the KERNO classifier is breaking down a series of clicks into several individual click trains while the whole series of clicks could realistically be categorised as a single click train exemplifying different phases. For this reason, all click trains within 1 second of each other are grouped together (Figure 4(b)). The click train detection and grouping is performed for the thirteen CPOD stations available (Section 2.4).

Results of these two ways of defining click trains are compared in Figure 7, showing the number of click trains per day for each station over the whole recording period. The results between the different CPOD stations can be highly variable, probably due to the difference in location for each CPOD. For example, there is a tenfold difference in the maximum number of train detections between stations GEM13 and GEM01. Most western CPOD stations showed very few click train detections (GEM01 to GEM04), especially for GEM03 and GEM04 which are not shown further in this report for this reason. CPOD stations in the middle of the offshore wind farms (GEM07 and GEM11) also show comparatively few detections. This could be due to higher noise levels (affecting the click detection effectiveness of the CPOD) or locations where the density of harbour porpoises is less. In general, eastern CPOD stations have the highest number of detections (e.g. GEM13). Figure 7 also compares the click trains using both the "CPOD.exe" software (red bars) and the 1 second interval click train regrouping (blue bars). As expected the regrouping results in lower numbers of click trains per day. Though, as shown in Figure 7, the 


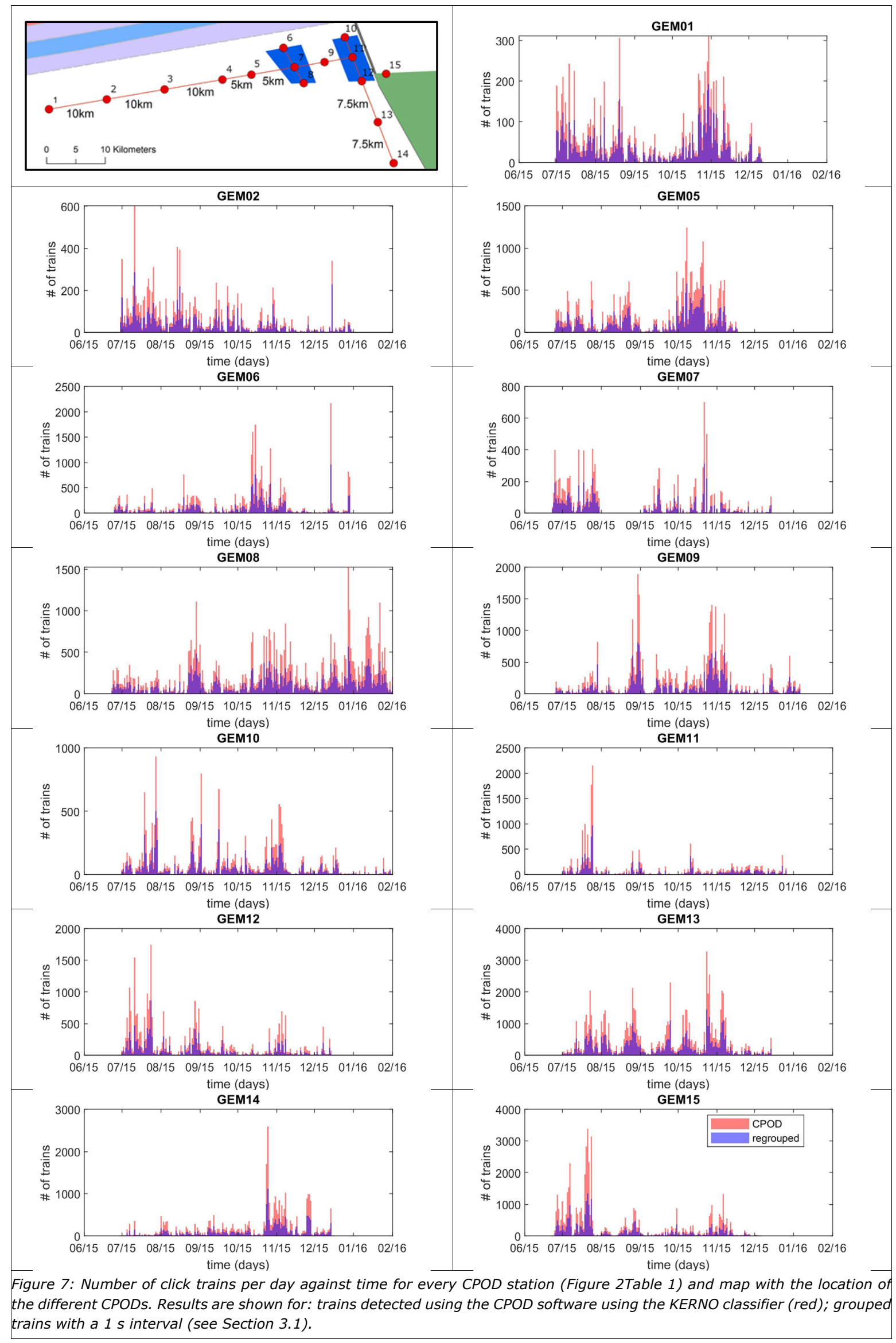


Based on the regrouped trains with the 1 second threshold, an automatic detection of foraging events is then applied (see Section 3.1 for description of the methodology). The aim is to identify the different phases typical of a foraging event from a harbour porpoise (Verfuss et al., 2009; Miller, 2010): search phase followed by an initial approach phase and a terminal approach phase. Though not modelled here, the final inter-click interval upsweep (terminal buzz) is also typical of a foraging event (region highlighted in a red circle in Figure 4) though not related to the success of the foraging event. Using the regrouped trains, a logistic function (Equation Equation (1)) is fitted to the ICI time series from each click train, resulting in optimized controlling parameters of the logistic function. These are further used to filter the click trains to those matching criteria typical of foraging events. These criteria are given in Section 3.1 (e.g. starting ICI in the time series, slope). The resulting number of detections of feeding events for each month for each CPOD station is shown in Figure 9.

As a result of the number of click trains detected for each station (Figure 7), the number of detected feeding events is highly variable between stations, with a maximum of 80 detection for GEM15 in August 2015. Overall, the number of detected feeding events is low, which reduces the applicability of this method. The poor detection rate is most likely due to the low number of ICI foraging event sequences that are fully resolved (i.e. detecting the different phases in the sequence, Section 3.1). In addition, though the detection accuracy is not systematically assessed in this study, manual scrutiny of the fitted ICI time series reveals miss classifications, i.e. false detections. An example is shown in Figure 8 . Whilst Figure 9(a) shows a complete time series that corresponds to a feeding event (including the terminal ICI upsweep although lower ICIs remain high), Figure 8(b) clearly shows a misclassification by the algorithm. The algorithm could be refined to filter out these false detections but the overall low number of detections (including miss classifications) suggests that deriving a feeding event index by identifying the full click train sequence is not robust enough, as it is only based on a marginal number of detections.

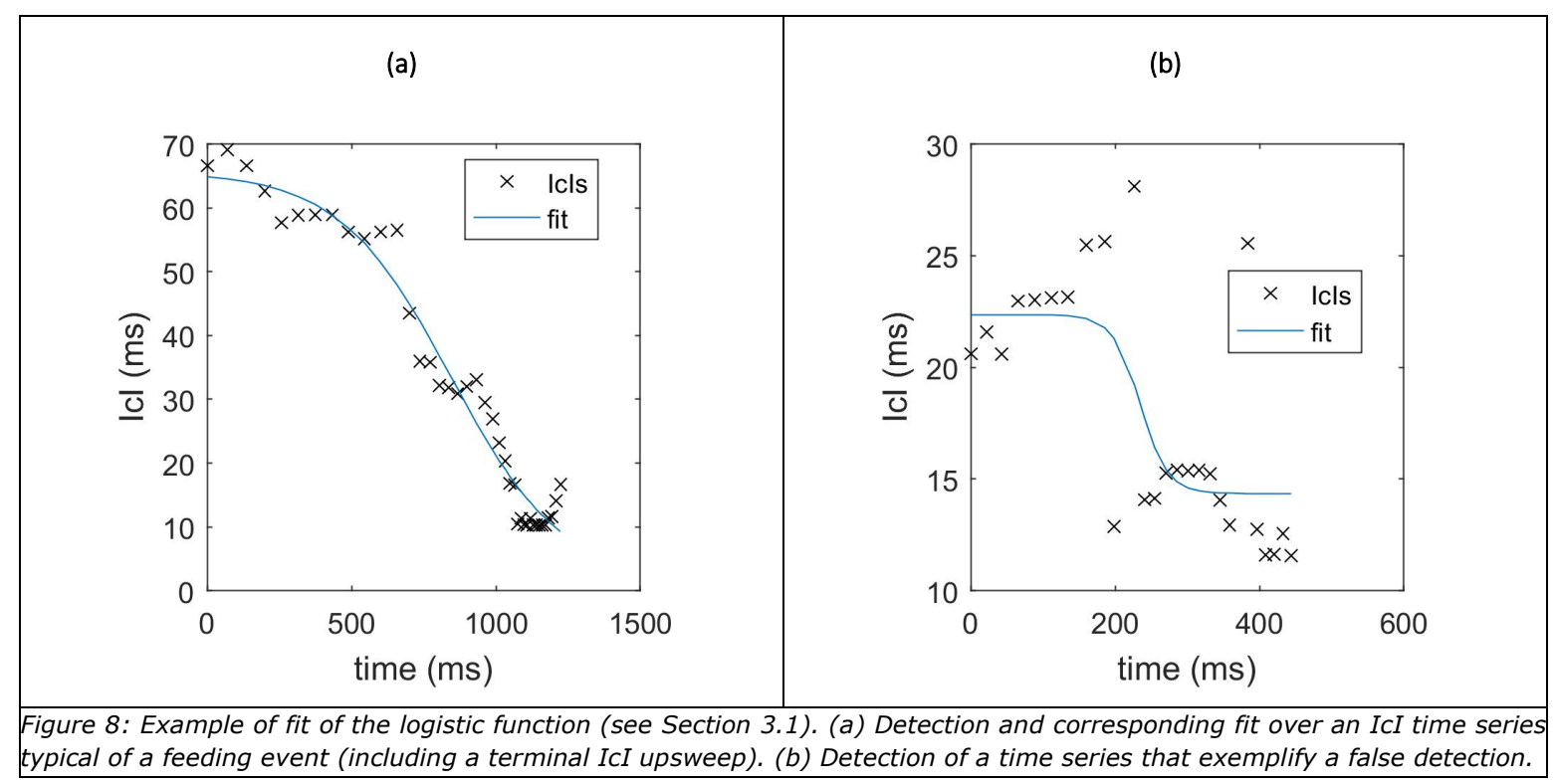




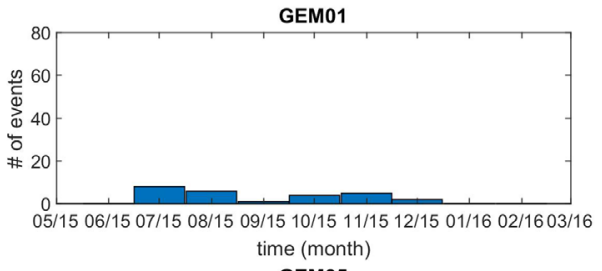

GEM05

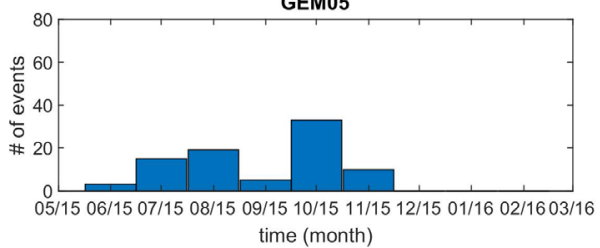
GEM07
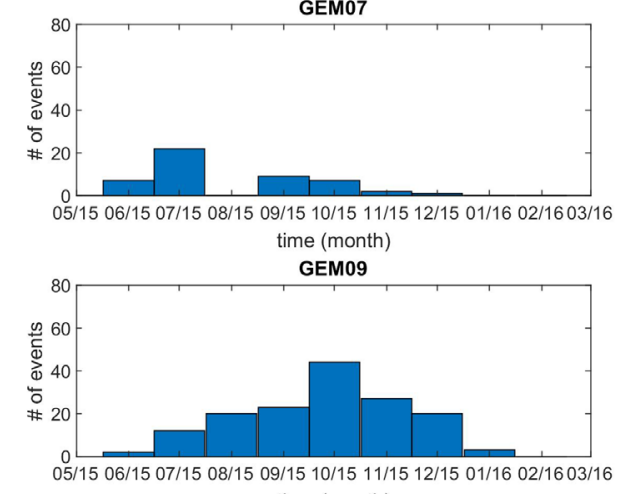

time (month)

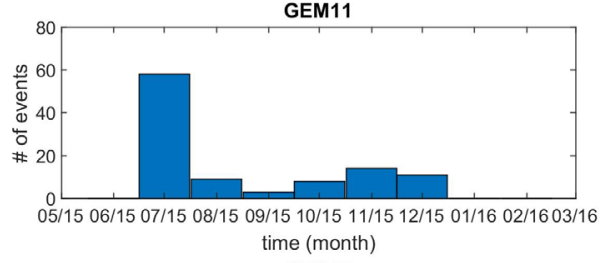

GEM13

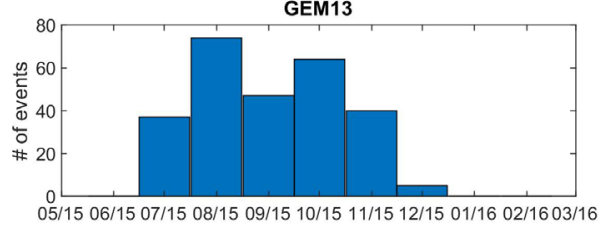

time (month)

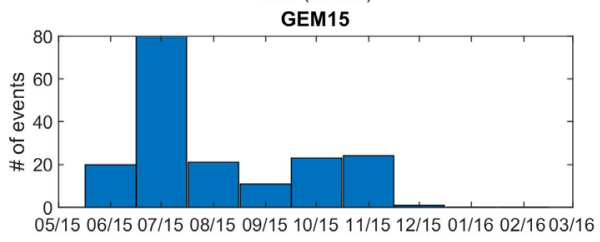

time (month)

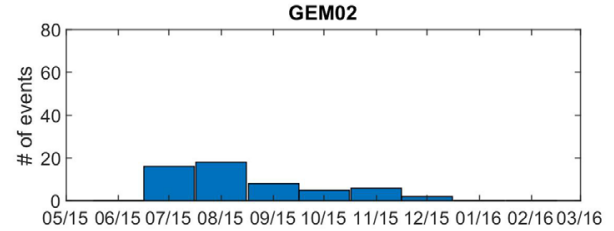

time (month)

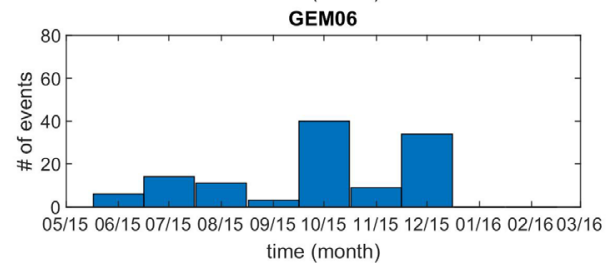

GEM08

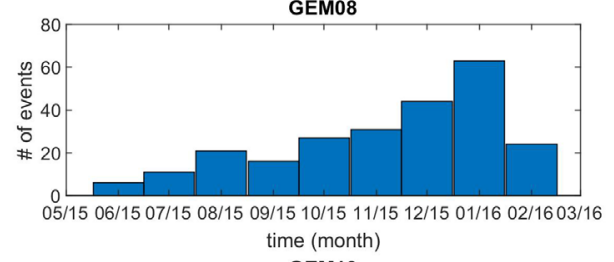

GEM10

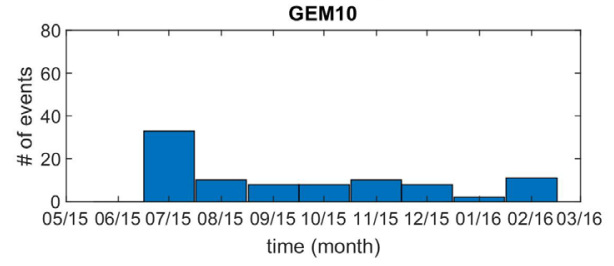

GEM12

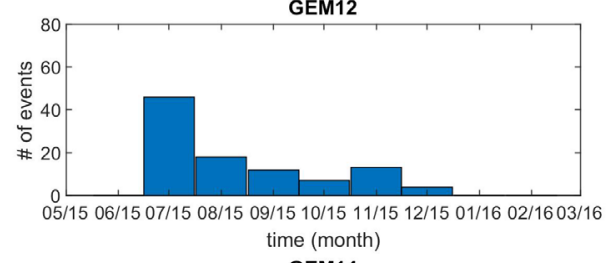

GEM14

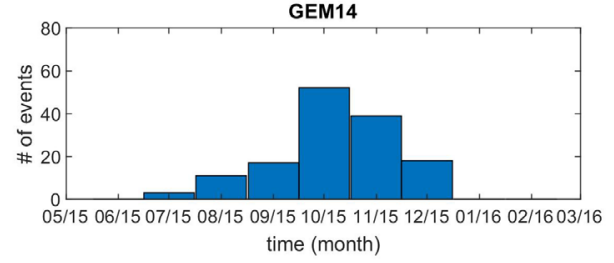

Figure 9: Number of detected foraging events per month using the logistic function fitting method (see Section 3.1) for all analyzed stations (Figure 2 and Table 1). 


\subsubsection{Click based methodology}

In the previous section, the algorithm used for the detection of foraging events based on click trains resulted in a very low number of detections. This is because the click trains based detection of foraging events relies on the ability to discriminate the different phases of such an event. Though such an approach was successfully implemented by Schaffeld et al. (2016), the data set used here only has few trains with a sequence of inter-click intervals typical of foraging events (Figure 9).

In this section, a method for the detection of feeding events based on individual clicks is used. More specifically, the click based methodology employed by Pirotta et al. (2014a,b) (described in Section 3.2) is applied. First, subsequent ICIs between all clicks from all stations are combined to obtain the overall distribution of ICIs for the data set. In order to increase the separation between the different ICIs, $\log (\mathrm{ICI})$ is used. The resulting distribution from the entire data set used here is shown in Figure 10 (right axis). It is clear that the distribution contains three components (Pirotta et al., 2014a,b). These correspond to:

- $\quad$ regular ICIs (regular clicking for navigation or prey searching)

- $\quad$ buzz ICIs (prey capture or social communication, Clausen et al., 2011, Sørensen et al., 2018)

- $\quad$ inter-train ICIs (i.e. pauses between click trains)

In order to separate these different components, a Gaussian mixture model is used to fit a probability density function (pdf) using three components. The resulting components are then used to cluster the different ICIs into the three categories above. The resulting pdf fitting the ICI distribution is shown in Figure 10 (thick lines, left axis). Buzz ICIs are then clustered using an agglomerative hierarchical cluster tree. It is important to note that the distribution shown in Figure 10 is fitted on the data from all CPOD stations. While a fixed ICI threshold (e.g. $10 \mathrm{~ms}$ ) could be used, using the method described here allows one to infer the ICI clustering from the data that are being used. The clicks classified using this method exemplify ICIs that are below 9.21 ms. Clicks (buzz clicks) associated with the filtered buzz ICIs are the basis for the analysis and discussion described further.

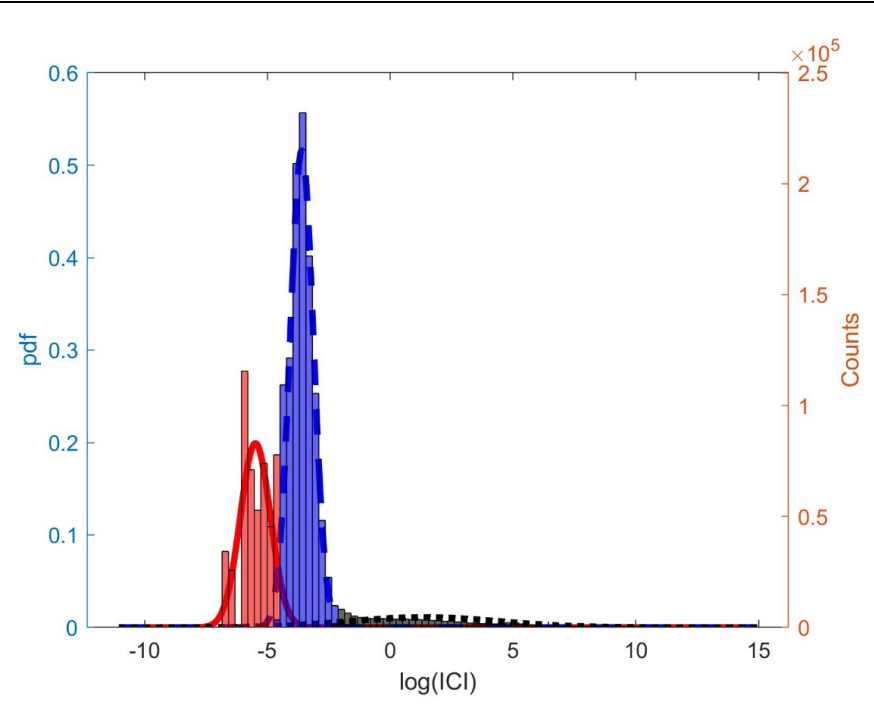

Figure 10: Three components Gaussian mixture model fitted on log(ICI) for all clicks detected on all the stations (Figure 2 and Table 1). The straight lines are the fitted pdf components (left axis) while the bars represent the histogram for the combined data (right axis). The colours represent the different components: regular ICIs (regular clicking for navigation or prey searching, blue), buzz ICI (prey capture or social communication, red), inter-train ICI (i.e. pauses between click trains, black).

The corresponding time series (number of buzz clicks per day over the recording period) for the detected ICIs is shown is Figure 11. The patterns are similar to the click train time series (Figure 7), since each buzz click is necessarily part of individual click trains.

The filtering employed only keeps clicks that are typical of possible prey capture or social communication (Clausen et al., 2011, Sørensen et al., 2018), thus making the time series more indicative of feeding events. The corresponding distribution of ICIs filtered (i.e. buzz ICIs) for all CPOD stations are shown in Appendix I (Figure I.3). These show a mode for the distribution around $5 \mathrm{~ms}$. The consistency of the 
distributions between the different stations suggest that the click activity over the recorded period is consistent.
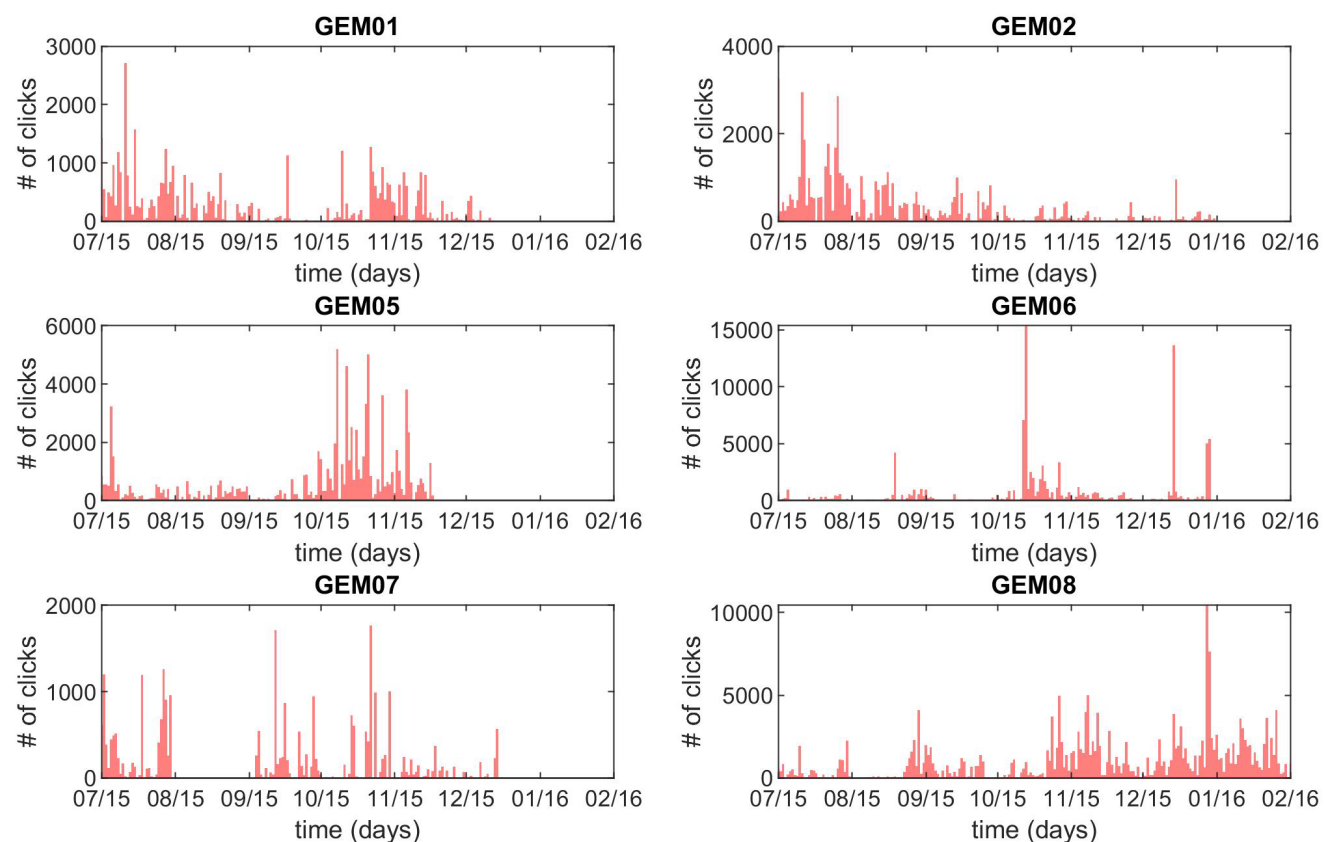

GEM09

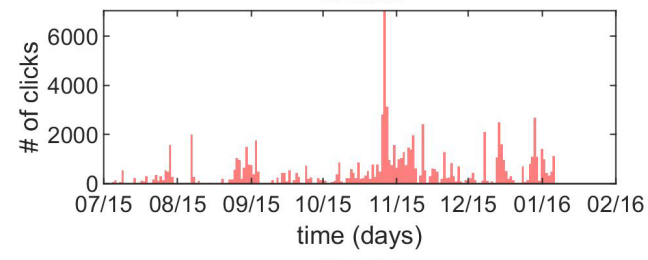

GEM10

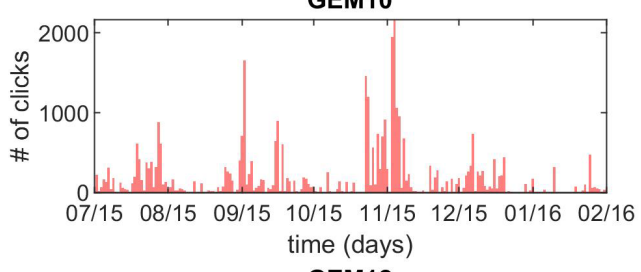

GEM12

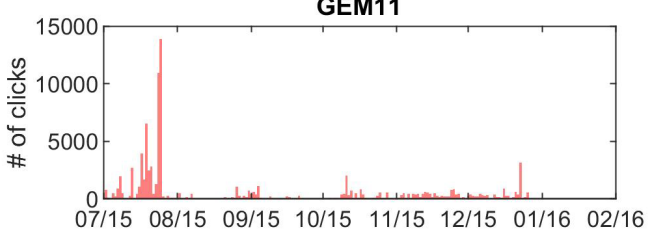

time (days)
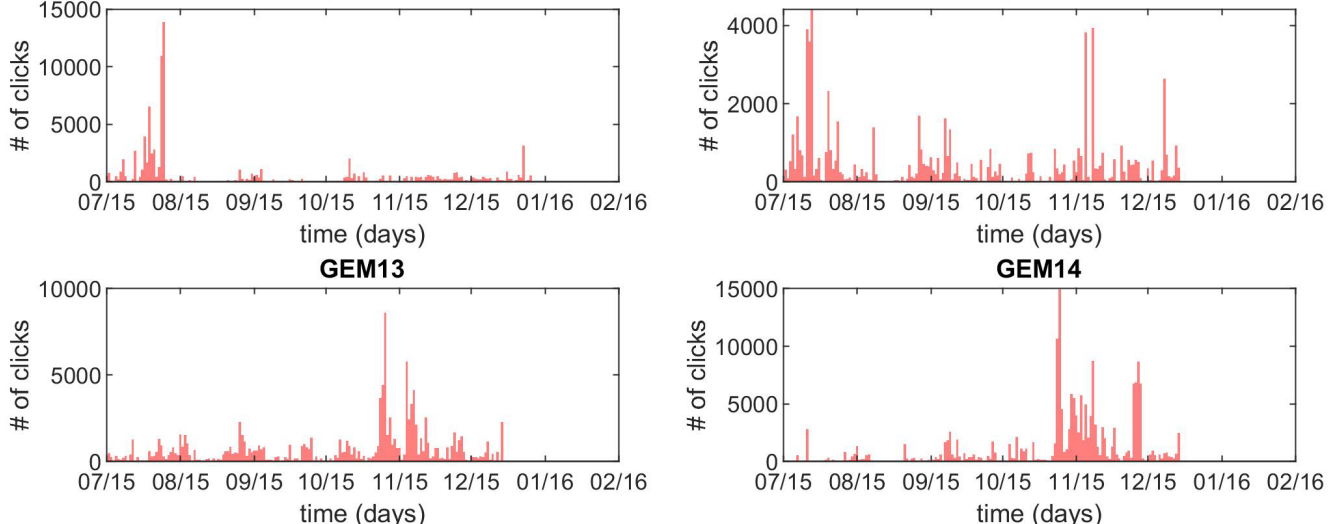

time (days)
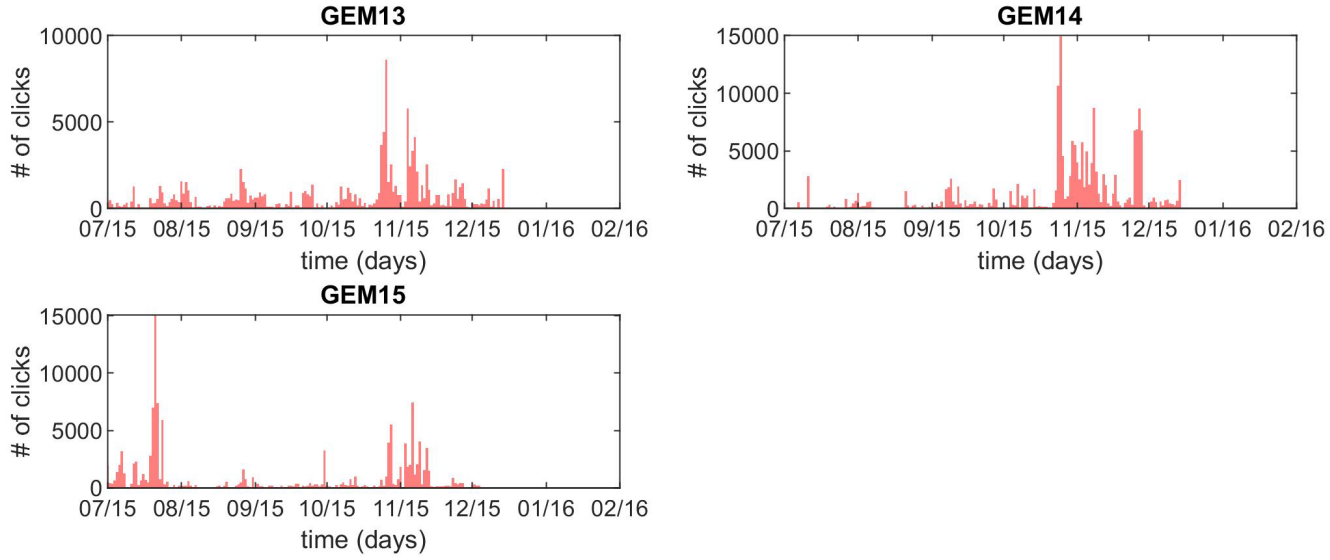

Figure 11: Number of clicks per day for the monitoring period for 13 CPOD stations (Figure 2 and Table 1). The clicks are selected using the method by Pirotta et al. (2014a,b) (Section 3.2). 


\subsection{Methods for automated detection of foraging events}

\subsubsection{Methodology comparison}

In the previous sections, the different time series for each CPOD station for each of the different methods employed are shown in:

- $\quad$ Figure 7 with the number of click trains per day.

- $\quad$ Figure 8 with the number of foraging events per month (detected using the methodology described in Section 3.1).

- $\quad$ Figure 11 with the number of buzz clicks per day determined using the method described in Section 3.2 (Pirotta et al., 2014 a,b).

These results are summarized in Table 2. Alongside the results presented in Figure 7 and 8, Table 2 provides the foraging event detection rate relative to the total number of trains detected.

Though for each station, the results from the different methods show similarities, they are representative of various aspects of harbour porpoise activities. The click trains time series (Figure 7) are representative of the overall occurrence of high-frequency clicks produced by porpoises. Here, the click trains are selected using either the KERNO classifier ("CPOD.exe") or a grouping based on a 1 second threshold (Section 3.1). Both types of click train sequence classifications result in very similar time series (Figure 7). The sequences of clicks provided by the KERNO classifier, however, are not suitable for resolving foraging events, because this classifier tends to break the different trains into small sequences. Using sequences of clicks grouped based on a 1 second threshold separation allows one to run the foraging event detection methodology described in Section 3.1 (fitting of logistic function, Equation (1)). However, as shown by the low number of detections shown in Figure 8, the performance of the detection is hampered by the difficulty to fully resolve the foraging event sequence. This low performance could be due to specific geographic setup of the CPOD at sea (location, depth), but also the high directionality of sound waves emitted by harbour porpoises (Miller 2010). As a result, any subtle change in heading direction of the porpoise affects the acoustic detection at the CPOD location dramatically (see for more on this section 4.3.3). In addition, it is important to note that the functionality of the CPODs itself further reduces the ability to detect foraging events. Hydrophones that allow full bandwidth acoustic recordings provide information such as click modulation in amplitude or bandwidth (due to the harbour porpoise itself or the acoustic propagation), features that can be informative for the classification of different events. Sarnocinska et al. (2016) showed the limitations of the CPOD data compared to full bandwidth recordings. This study found discrepancies between the systems with fewer click detections provided by the CPOD unit.

Though it is highly unlikely to obtain representative samples of entire foraging events from stationary PAM systems (either CPODs or classical hydrophones), it is clear that a substantial number of detected clicks is part of foraging sequences. This motivates the use of individual clicks rather than click trains for the assessment of: (1) the level of foraging and more specific feeding activity and (2) the change in foraging behaviour (e.g. increasing/decreasing). Using the click train approach (Section 3.2), clicks are reduced to those related to communication and foraging activity.

The results for each station are plotted in Figure 11 and summarized in Table 3. For each CPOD station, Table 3 also provide the mean of the daily buzz click ratio. For a given day, the daily buzz click ratio defined by:

$$
\begin{array}{l|l}
R_{\text {buzz }}=\frac{N_{\text {buzz clicks }}}{N_{\text {clicks }}} & \text { Equation (2) }
\end{array}
$$

With $N_{\text {buzz clicks }}$ the number of buzz clicks in a day and $N_{\text {clicks }}$ the total number of clicks in that day. The quantity $R_{\text {buzz }}$ is representative of the change in proportion between high ICIs and low ICIs. The limit between low and high ICIs is defined as $\sim 10 \mathrm{~ms}$ by the fitting of the Gaussian mixture model (Section 3.2). 
Table 3: Summary of results from the click train based method (Section3.1) and click based method (Section 3.2). The number of detected foraging events per train represent the detection rate using the method described in Section 3.1 for a given CPOD station. The mean daily buzz click ratio is the mean of the ratio of number of buzz clicks (selected using method described in 3.2) by the total number of detected clicks.

\begin{tabular}{lllllll}
\hline CPOD ID & $\begin{array}{l}\text { Monitoring } \\
\text { period } \\
\text { (\# of days) }\end{array}$ & $\begin{array}{l}\text { \# of trains } \\
\text { (1 second } \\
\text { threshold) }\end{array}$ & $\begin{array}{l}\text { \# of detected } \\
\text { foraging } \\
\text { events }\end{array}$ & $\begin{array}{l}\text { \# of } \\
\text { detected } \\
\text { foraging } \\
\text { events per } \\
\text { train }\end{array}$ & $\begin{array}{l}\text { \# of buzz } \\
\text { clicks }\end{array}$ & $\begin{array}{l}\text { Mean } \\
\text { daily buzz } \\
\text { click ratio }\end{array}$ \\
\hline GEM01 & 178 & 10083 & 26 & 0.0026 & 44052 & 0.25 \\
GEM02 & 187 & 12564 & 55 & 0.0044 & 54713 & 0.26 \\
GEM05 & 148 & 33095 & 85 & 0.0026 & 96775 & 0.24 \\
GEM06 & 190 & 32771 & 117 & 0.0036 & 110028 & 0.25 \\
GEM07 & 177 & 11474 & 48 & 0.0042 & 47473 & 0.23 \\
GEM08 & 241 & 57693 & 243 & 0.0042 & 233896 & 0.28 \\
GEM09 & 198 & 40691 & 151 & 0.0037 & 145640 & 0.23 \\
GEM10 & 232 & 21007 & 90 & 0.0043 & 50364 & 0.20 \\
GEM11 & 181 & 20372 & 103 & 0.0051 & 103502 & 0.26 \\
GEM12 & 169 & 29577 & 100 & 0.0034 & 93149 & 0.27 \\
GEM13 & 169 & 81938 & 267 & 0.0033 & 135688 & 0.20 \\
GEM14 & 168 & 34416 & 140 & 0.0041 & 198289 & 0.28 \\
GEM15 & 165 & 53942 & 245 & 0.0045 & 158980 & 0.24 \\
\hline
\end{tabular}

A comparison between the click trains and buzz clicks time series is shown in Figure 12. Because both quantities are different, the time series undergo a $\mathbf{Z}$ normalization prior to their comparison. For both time series, the $Z$ normalization ensures a mean of 0 and a standard deviation close to 1 . In addition, a 5 day rolling average is applied to each time series to reveal smoother long term trends while keeping weekly patterns. For this comparison, CPOD stations GEM08 and GEM13 are chosen as examples. These stations are selected as they have a large number of detections in terms of click trains, feeding events and buzz clicks (

Table 3). Plots for all CPOD stations are given in Annex I (Figure I.4). From Figure 12, it can be observed that the pattern of click trains and buzz clicks varies substantially over time. For GEM08 (Figure 12(a)), both click trains and buzz clicks follow similar trends. For GEM13 (Figure 12(b)), while the variation in click trains and buzz clicks is similar, the rate of increase from $15^{\text {th }}$ October is larger for buzz clicks than for click trains. The later shows that the number of trains is not necessarily representative of the number of buzz clicks (encompassing both communications and feeding).

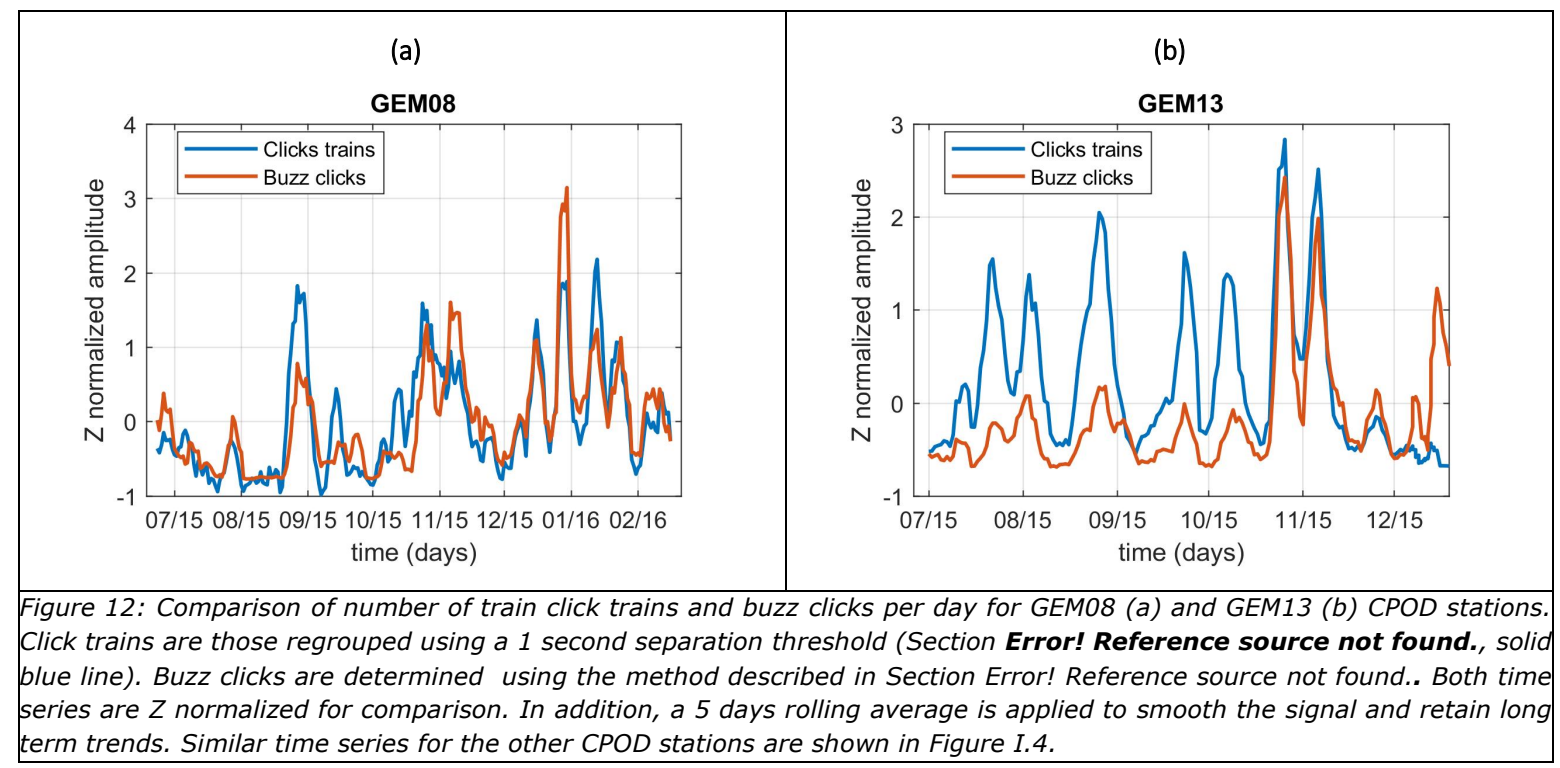




\subsubsection{Buzz clicks detection algorithm}

The two methods presented here (click train based approach, Section 3.1 and click based approach, Section 3.2) aim at consistently identifying either foraging behaviour using click trains or feeding behaviour using clicks. The results from the click train based method (Section 4.1.1) clearly showed limitations due to the ability of the CPOD to resolve full foraging sequences. As a result, the number of detected foraging events is low (maximum of 80 events per month for GEM 15) which would hamper any subsequent analysis due to low representativeness. Motivated by this limitation, the method by Pirotta et al. (2014a,b) is applied and the results are presented in Section 4.1.2. This method filters the different clicks using the separations between buzz ICIs, regular ICIs and inter-train ICIs. Then, clicks associated with buzz ICIs can be selected. Table 3 illustrates the difference in detected event and clicks using these two methods. It is important to note that buzz ICIs are associated with either communication or feeding (Clausen et al., 2011, Sørensen et al., 2018).

The process for the detection of buzz clicks is described in Section 3.2. Figure 13 shows a data processing flow diagram for a data set composed of N CPOD stations. The processing consists of three main steps:

1. Classifying click trains using the KERNO classifier

2. Filtering click trains to NBHF and those presenting medium and high quality (i.e. not selecting low quality clicks to avoid false positives).

3. Apply a three components Gaussian mixture model on ICI across all CPOD stations.

4. Use an agglomerative hierarchical cluster tree to cluster the three different groups of ICIs. The buzz ICIs correspond to the group with the lowest mean ICI.

5. Reassign the clustered buzz clicks to the different CPOD stations.

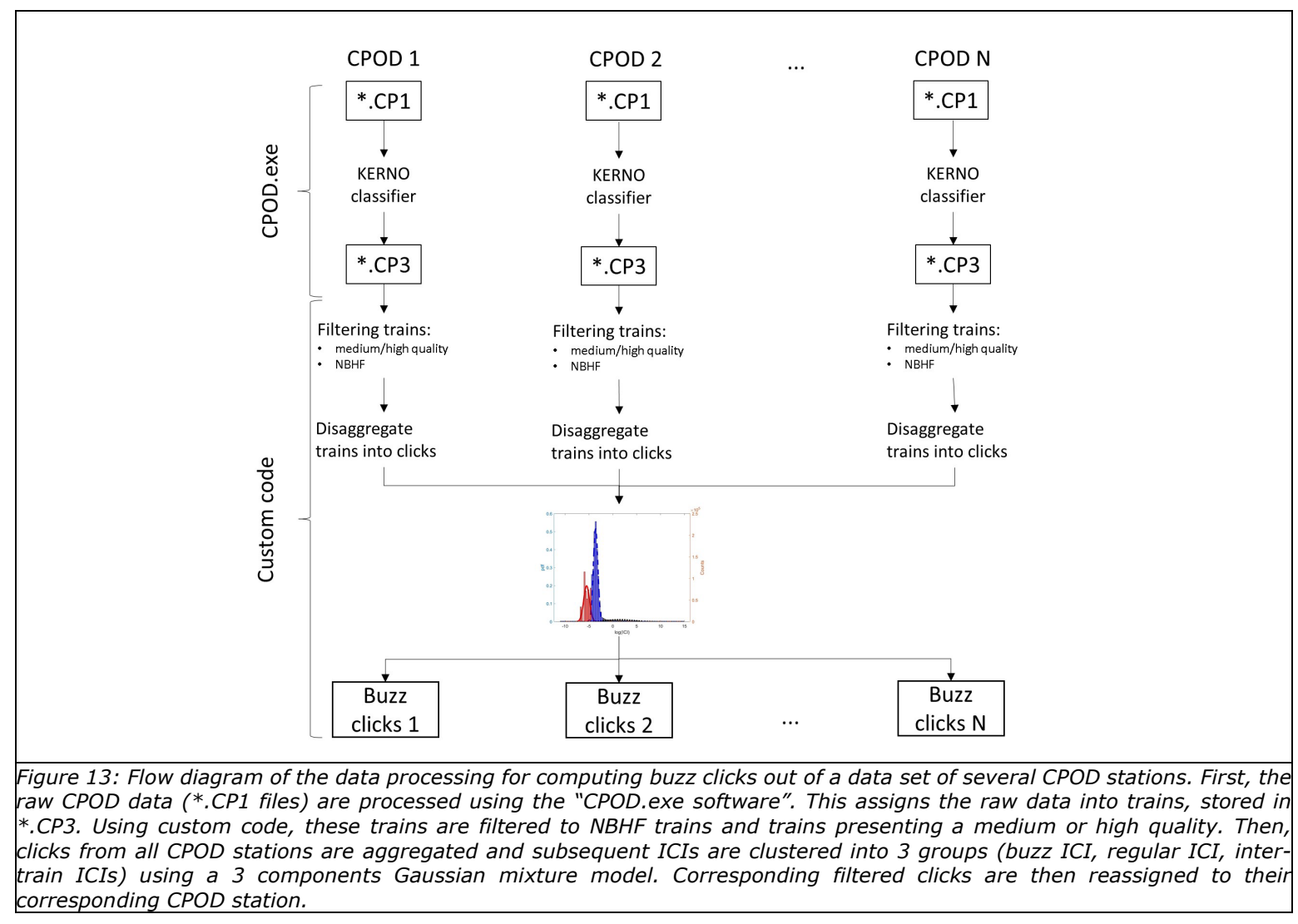




\subsubsection{Changes over time and between stations}

The proportion of buzz clicks relative to the total number of clicks, the so called "buzz click ratio" (Equation (2)), is indicative of behavioural changes. Buzz clicks are associated with prey capture or social communication (Clausen et al., 2011, Sørensen et al., 2018). Thus, an increase in the buzz click ratio indicates an increase of communication or feeding activities relative to the total click activity of the porpoise. How this influences the interpretation of the data is discussed in section 4.3.3.

Similarly to Figure 12, GEM08 and GEM13 stations are chosen as examples to show changes in buzz click ratio. This is shown in Figure 14 where buzz clicks per day (solid blue lines) are overlaid with buzz click ratios per day (solid red lines). In order to filter out short-term variations, a 5 days rolling average is applied to smooth each time series. For both stations the buzz click ratio varies greatly prior to November 2015 and oscillate around $\sim 0.3$ after November 2015. This could be indicative of a more consistent foraging behaviour after November 2015.
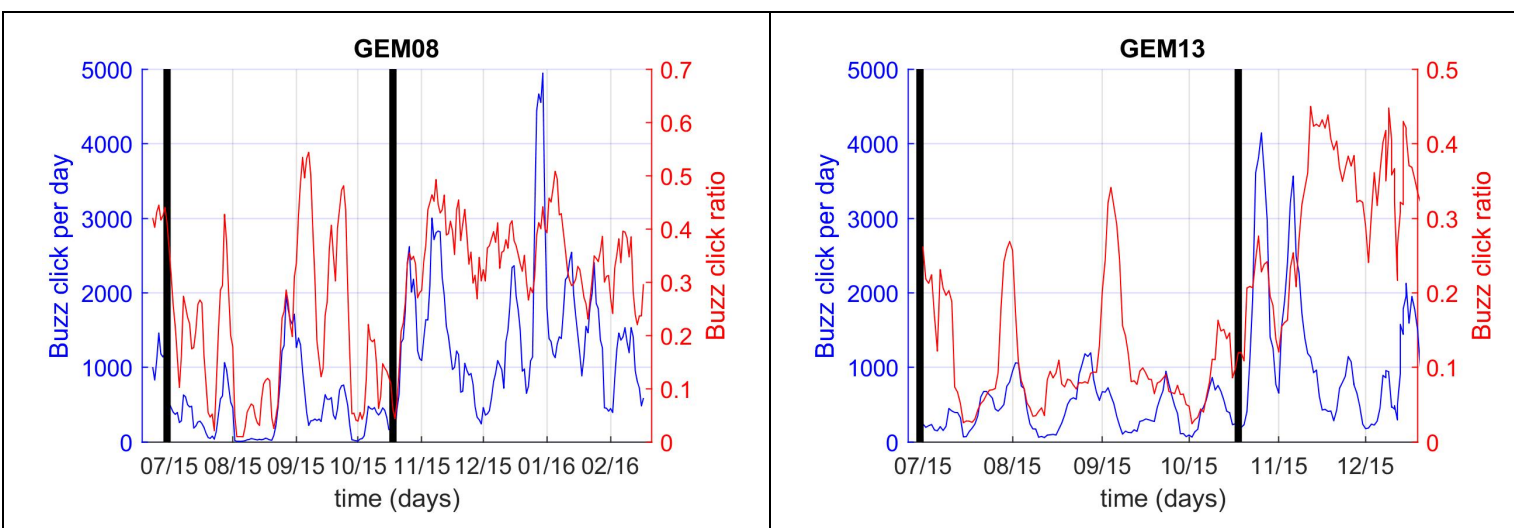

Figure 14: Buzz clicks per day and corresponding buzz ratio for GEM08 and GEM13 CPOD stations. A rolling average of 5 days is applied to the time series in order to reveal long term trends. The buzz click ratio is computed as in Equation (2) and is indicative of behavioural change. The vertical black lines indicate start and end of piling noise activities. The comparison with exposure level (i.e. relative to level pile driving and location) for each CPOD station is given in figures 15 and in Appendix I (Figure I.6 for buzz clicks per day and Figure I.7 for buzz click ratio).

\subsubsection{Relation to pile driving activities}

From $30^{\text {th }}$ June 2015 to $18^{\text {th }}$ October 2015, pile driving took place in both Gemini wind farms (Figure 2). The timing and intensity of these activities are plotted in Figure I.1 and I.2. Furthermore, in order to relate the exposure to pile driving noise at the different CPOD stations, an exposure level relative to the given CPOD location is computed as follows:

$$
E=\frac{I}{d^{2} \times \Delta t} . \quad \text { Equation (3) }
$$

With $I$ the energy for the pile driving event $(\mathrm{kJ}), d$ the distance between the pile driving location and the CPOD location $(\mathrm{km}), \Delta t$ the duration of the pile driving event (s). The resulting plots for all CPOD stations are shown in Annex I (Figure I.6 for buzz clicks per day and Figure I.7 for buzz click ratio). As an example, GEM08 and GEM13 are shown in Figure 15. These two stations are selected because they exemplify similar setup in the western (GEM08) and eastern (GEM12) parts of the Gemini offshore wind farm, respectively ZeeEnergie and Buitengaats (Figure 2). Figure 15 shows that the buzz click ratio clearly increases after the stopping of the piling activity, increasing from a long term mean of $\sim 0.1$ toward a ratio of $\sim 0.3$. This change in ratio could be indicative of the disturbance of piling activity on foraging behaviour. More specifically, the increase in ratio relates to the increase of foraging of harbour porpoises in the vicinity of the CPOD. The lower buzz click ratio levels during pile driving activity indicate a negative impact on foraging. A recent analyses of the results from tagged porpoises shows that vessel noise can negatively impact foraging (Wisniewska et al. 2018), indicating that foraging behaviour might be a good indicator for behaviour change due to noise. 


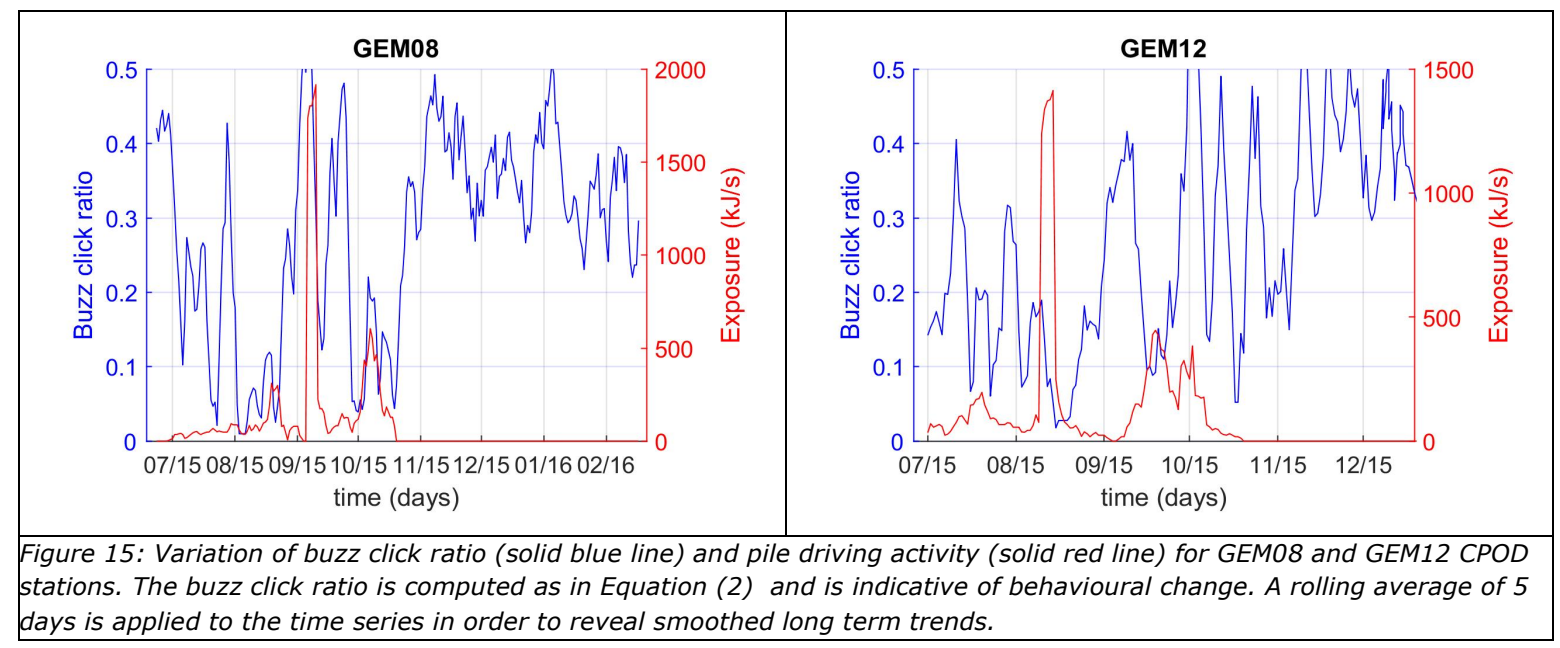

\subsection{Limitations}

One ultimate goal in studying foraging behaviour of porpoises using PAM is to estimate the absolute or relative feeding activity of porpoises in the area where the PAM equipment is deployed. However, for now, there is a number of limitations to how the data collected can be used. Some of these are general to CPOD devices, others are specific challenges to obtaining data on foraging behaviour. In this section we provide an overview of the most relevant points to consider.

\section{The CPOD}

As we described earlier, the CPOD is not providing full-spectrum data on the sounds recorded. This allows the device to operate for a long time as a self-sustained system, but it does mean that potentially useful information on the characteristics of porpoise clicks is lost. This can be alleviated using classical hydrophones but bring limitations in term of the monitoring period (storage and battery life). The soundtrap system offer a viable alternative with full spectrum recording coupled with a click detection algorithm that limits the amount of data stored.

\section{CPOD placement}

To ensure the best performance, the advice of Chelonia Ltd. (2012) is to place CPODs about $2 \mathrm{~m}$ above the sea bed and at least $5 \mathrm{~m}$ below the water surface. The characteristics of different locations can vary substantially between sediment type, seafloor characteristics as well as oceanographic characteristics such as water temperature, currents, depth and salinity. All of these can directly or indirectly influence the transmission loss from porpoise vocalisations and thus the recording ability of the device (De Ruiter et al., 2010). Background noise can also vary and affect the detection probability of porpoise clicks (Clausen et al., 2018). These potential issues should be taken into account when selecting the location of CPODs.

\section{Porpoise behaviour}

Observation of feeding behaviour of harbour porpoises in the wild is very rare. However, we do know that their prey in the North Sea can be highly variable, ranging from benthic species such as gobies to pelagic fish such as herring, sprat and cod (Jansen et al., 2013). It is likely that their foraging tactics will change depending on prey type, availability and size, which will vary between different areas, between years as well as seasons (Santos and Pierce, 2003). Furthermore, there are differences in prey type between individuals (Leopold, 2015). For example, porpoises will scan the sea bottom with their sonar to find benthic fish (Linnenschmidt et al., 2013). To hunt pelagic fish they would probably scan their environment in a different way. Either of these tactics will have an impact on how effectively sound is recorded by a stationary hydrophone, especially given the narrow beam and directionality of a harbour porpoise sonar (Villadsgaard et al. 2007). Furthermore, hunting strategies might also depend on daytime, as shown by five porpoises tagged in Danish waters. During day they showed near-surface, pelagic, and benthic foraging, while during night they performed primarily pelagic dives (Wisniewska et al., 2016). 


\section{Narrow beam}

As we mentioned earlier, the beam of the harbour porpoise sonar is very narrow and directional Villadsgaard et al., 2007). A good analogy is using a flashlight to orientate oneself in the dark. The animal will continuously move its head to scan the environment. Any PAM device will thus have limitations in how much of the continuous sound emissions can be detected - unless the porpoise uses the device as a target and directs the beam directly at it. One way to obtain all acoustic emissions - and thus also complete foraging sequences - in the wild is the use of acoustic tags on the porpoise itself (e.g. Wisniewska et al. 2016). This type of studies can provide knowledge on a porpoise's use of sonar and insight in the performance of a PAM device in regard to detection probability of feeding buzzes and false alarm rates. At this point the sample size of tagged porpoises is still very small.

\section{Social vs foraging behaviour}

Using the click based approach described in Section 3.2 (Pirotta 2014a,b), one is able to discriminate buzz clicks from the entire grouping of clicks. However, the classified clicks include clicks related to foraging as well as communication. If the ratio between foraging and communication remains constant, the number of buzz clicks detected is directly proportional to the number of clicks related to foraging behaviour. The number of buzz clicks can therefore be used as an index of foraging. However, in order to relate such an index to an absolute level of feeding events, the number of buzz clicks per feeding event should be determined. This could be calculated by close scrutiny of the data to find well defined foraging sequences or by means of more explicit acoustic data (i.e. full-spectrum hydrophone data). In the case of the data presented in this report, the detection of foraging sequences that are fully resolved is low and one would need complementary full-spectrum hydrophone data in order to infer the number of buzz clicks per feeding event.

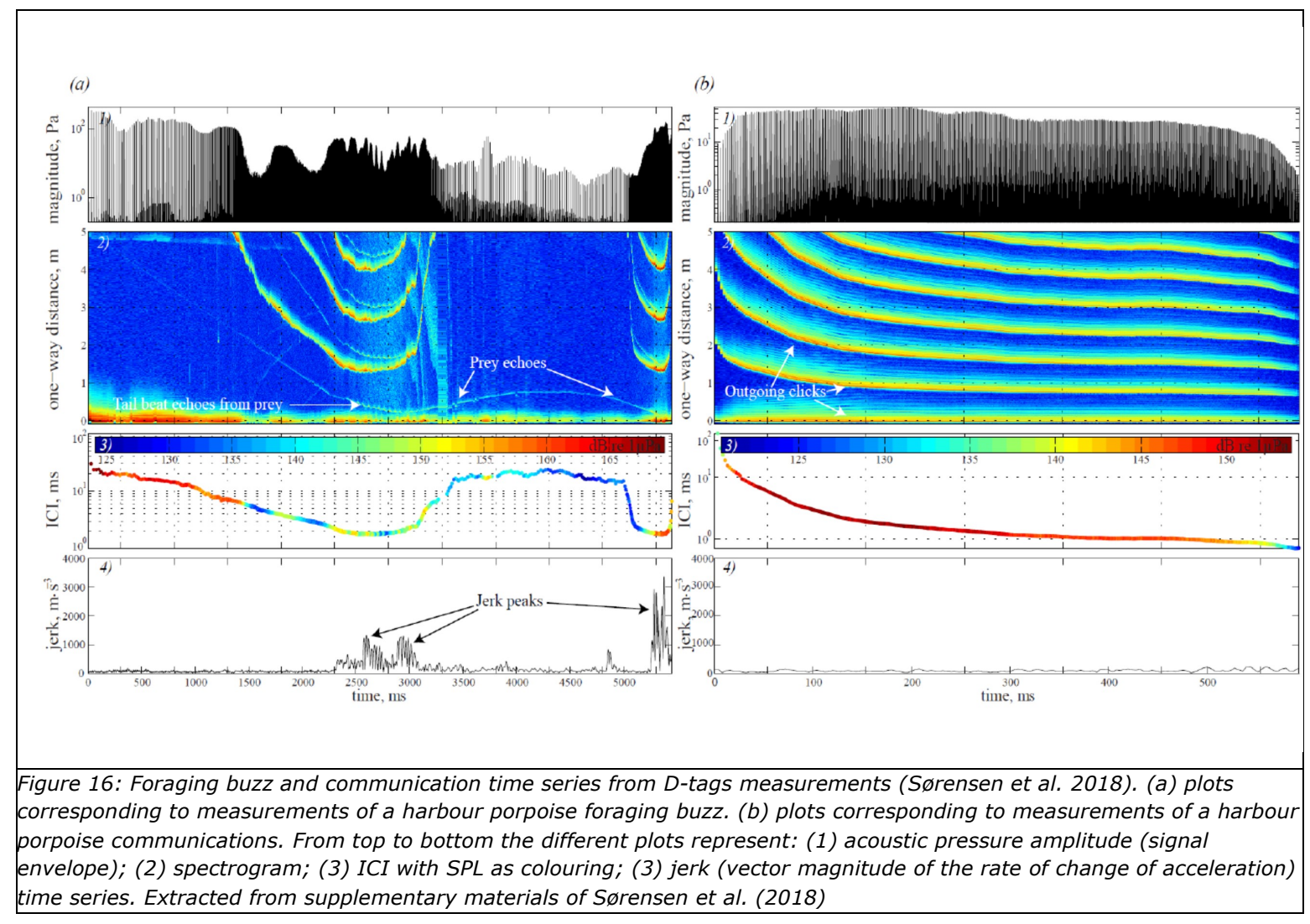

An important point to consider is if the assumption that the proportion of calls and foraging activities is not valid, then communication clicks need to be differentiated from foraging clicks. Prior to considering the direct detection of foraging clicks from a fixed PAM station, it is interesting to examine the acoustic signatures as recorded by $\mathrm{D}$-tags of both communication and foraging events. To that purpose, the recently published study by Sørensen et al. (2018) is very relevant. It is important to note that in order to differentiate between communication calls and foraging events, Sørensen et al. (2018) used accelerometers and acoustic measurements. Acceleration measurements of the harbour porpoise are 
used to compute the normalized jerk which is defined as the magnitude of the rate of change in acceleration. High jerk peaks (i.c. rapid accelerations) are characteristic of prey capture for harbour porpoises (Sørensen et al., 2018; Wisniewska et al., 2016). Figure 16 shows acoustic and jerk recordings from a communication call and a foraging event. While the change in ICI is characteristic for feeding events, it is interesting to note that the modulation in amplitude with time differs greatly from communication calls. This could potentially be used to separate buzz clicks between foraging and communication. Though possible, the use of the latter acoustic amplitude from a fixed PAM station is challenging as the recorded levels at the receiver location are not only dependent on the acoustic source (emission level, directivity) but also on the acoustic waveguide (Urick, 1996).

\section{Foraging vs feeding}

We are often using the term foraging and feeding in the same context. However, a porpoise will not always be able to catch a fish even if we see a perfect approach phase etc. It is important to note that we cannot separate buzzes between successful and failed attempts in prey capture. Some information on the rate of successful capture vs attempts could be derive from the results of tagging studies (Sorensen et al., 2018; Wisniewska et al., 2016). However it is likely that the catch rate is highly dependent on the available prey, as well as the experience of the porpoise.

At this point we cannot say for certain how often a feeding buzz indicates a successful prey capture. So the results should be interpreted as foraging behaviour in general, not feeding events. 


\section{$5 \quad$ Conclusions and recommendations}

\subsection{Conclusions}

The comparison of the different analytical options has shown that even though defining foraging behaviour from CPOD data is not trivial, we can propose a best practice going forward. One point we highlighted is that in our analyses we assume that all buzzes represent foraging behaviour. However, buzzes with ICIs smaller than $2 \mathrm{~ms}$ can also be associated with calls expressing pain, distress, dominance or aggression (e.g. Amundin, 1991) or with investigating objects close by such as a hydrophone or foraging near the seabed (Verboom and Kastelein, 1995). For now we are assuming that the occurrence of non-foraging buzzes are a constant or at least random source of potential false positives. But future studies on harbour porpoise's acoustic signals in relation to their behaviour are needed to verify (or falsify) this. A more in depth look into the very recent results from the tagging studies (e.g. Sørensen et al., 2018; Wisniewska et al. 2016) could be helpful for this purpose.

A large number of studies have shown that CPODs can be an effective method to monitor how harbour porpoises use their habitat as well as the impact of human activities (e.g. Brandt et al., 2014; Dähne et al., 2013; Scheidat et al., 2011; Pirotta et al., 2014b). Even though we identified a number of caveats associated with this method in general as well as with the detection of foraging behaviour, it is important to recognize that the comparison of an index of behaviour is possible. With the assumption that most of the limitations are constant, foraging behaviour can be quantified in sufficient numbers from CPOD data to detect patterns over time, such as diel patterns, as well as to compare stations or to compare the patterns associated with noise emitting activities like pile driving. For future research projects that include the investigation of foraging behaviour, it would be preferable to use full-spectrum hydrophones with the ability to measure the acoustic pressure itself.

The ability to potentially quantify foraging behaviour (and potentially other types of behaviour) opens a range of new opportunities to obtain answers to some pending questions. As an example, if feeding buzzes can be translated into foraging activity of harbour porpoises at sea, this information could be compared with data on physiology and feeding behaviour of captive porpoises (SEAMARCO) to better assess the impact (on an individual an population level) of interrupted foraging (Kastelein et al 2019).

We also show that the buzz click ratio can indicate changes in how an area (e.g. wind farm) is used over time. During the construction phase of the Gemini wind farm a reduction of harbour porpoise click activity, generally interpreted as a (short-term) displacement of animals, was found (Geelhoed et al., 2018). Our results further suggest a reduction in their foraging behaviour as well. A detailed (GAM) analysis of feeding events during the construction phase at different locations around a wind farm can provide more insight on this.

Changes in buzz click ratios can be particularly interesting if this type of data could be collected in an operational wind farm over several years. One common theory is that wind farms serve as a sort of "refuge" to porpoises as they have a higher prey availability than the surrounding area. If there is a difference or if there are changes in foraging activity, this should be translated to effects on porpoise fitness and eventually feed into population models ${ }^{34}$ (Nabe-Nielsen et al. 2017, Nabe-Nielsen et al. 2016, Pirotta et al. 2018) to predict the effects of offshore wind farms on a larger scale. It would also provide baseline data to assess the potential impact of fishery inside wind farms on harbour porpoises.

Most habitat models for porpoises currently use data on fish distribution to predict the distribution and (relative) abundance of porpoises. However, with very variable data quality and resolution, in the North Sea, it is not a good explanatory variable. Foraging behaviour could be linked directly to parameters

\footnotetext{
${ }^{3}$ http://www.smruconsulting.com/products-tools/pcod/

${ }^{4}$ http://www.depons.au.dk and https://github.com/jacobnabe/DEPONS
} 
such as season, time of day and tide, or prey distribution and availability, widening our understanding of how porpoises use their habitat.

\subsection{Recommendations}

Our recommendation in terms of the best methodological approach:

- To analyse existing CPOD data with regard to foraging behaviour of harbour porpoise, the Pirotta et al 2014 a, b approach seems to be the most adequate. We recommend to make the analytical tool we developed available for people interested in applying it to data collected with CPODs.

We also recommend to apply the automated methodology to a larger database to investigate the following specific research questions:

- Hypothesis I: Wind farms are an "oasis" for harbour porpoises as they provide more prey

- Is there a difference in foraging activities in operational wind farms compared to the surrounding area?

- Is there a change in foraging activities over time, from pre-construction to operation, indicating a change in prey availability?

- Hypothesis II: Foraging activity is reduced during construction activity of wind farms

- During the construction phase we can see a reduction of click activity. But does this translate to a (short-term) displacement of animals only, or also to a reduction in their foraging behaviour? How would a reduction in foraging impact the energy budget of harbour porpoises?

- Hypothesis III: Foraging activity is related to environmental parameters such as month, time of day and tide

- Porpoises in the North Sea are considered generalists in terms of prey consumption. Can the foraging data be used to identify patterns of behaviour linked to prey distribution and availability? E.g. is there a spatial relationship between prey occurrence (e.g. during a certain time period) and porpoise foraging clicks?

Finally, this work has triggered several additional questions and options in terms of how the analyses of CPOD data could be improved. While not part of the aim to quantify foraging behaviour, this could be of general interest to facilitate and streamline CPOD data analyses in an international framework. As a final point, we believe these results could be useful for other research questions related to the WOZEP aims and as such their potential should be discussed with specialists from other areas of expertise. 


\section{Acknowledgments}

We would like to thank Gemini Windpark for their interest in this project and for providing us with the data set used in our analyses. 


\section{$7 \quad$ Quality Assurance}

Wageningen Marine Research utilises an ISO 9001:2015 certified quality management system. This certificate is valid until 15 December 2021. The organisation has been certified since 27 February 2001. The certification was issued by DNV GL. 


\section{References}

Amundin M (1991) Sound production in odontocetes with emphasis on the harbour porpoise. Stockholm University PhD thesis.

Brandt MJ, Hanses S, Diederichs A and Nehls G (2014) Do man-made structures and water depth affect the diel rhythms in click recordings of harbour porpoises (Phocoena phocoena)? Marine Mammal Science 30(3): 1109-1121.

Brasseur SMJM, Van Polanen-Petel T, Geelhoed SCV, Aarts GM and Meesters HWG (2010) Zeezoogdieren in de Eems 2009: overzicht van de verkregen data. Research Report IMARES Wageningen UR Institute for Marine Resources \& Ecosystem Studies, Report C023/10.

Camphuysen CJ and Siemensma ML (2011) Conservation plan for the Harbour Porpoise Phocoena phocoena in The Netherlands: towards a favourable conservation status. NIOZ Report 2011-07, Royal Netherlands Institute for Sea Research, Texel.

Carlström, J (2005) Diel variation in echolocation behaviour of wild harbour porpoises. Marine Mammal Science 21: 1-12.

Chelonia Ltd. 2012. Manual for CPOD.exe; [cited 2012 Jun 1]. Available from: http://www.chelonia.co.uk/downloads/CPOD.pdf

Clausen KT, Wahlberg M, Beedholm K, De Ruiter S and Madsen PT (2011) Click communication in Harbour Porpoises Phocoena phocoena. Bioacoustics 20(1): 1-28.

Clausen KT, Tougaard J, Carstensen J, Delefosse M and Teilmann J (2018) Noise affects porpoise click detections - the magnitude of the effect depends on logger type and detection filter settings. Bioacoustics DOI: 10.1080/09524622.2018.1477071

Dähne M, Gilles A, Lucke K, Peschko V, Adler S, Krügel K, Sundermeyer J and Siebert U (2013) Effects of pile-driving on harbour porpoises (Phocoena phocoena) at the first offshore wind farm in Germany. Environmental Research Letters 8: 025002.

De Ruiter S, Hansen M, Koopman HN, Westgate AJ, Tyack PL and Madsen PT (2010) Propagation of narrow-band-high-frequency clicks: measured and modeled transmission loss of porpoise-like clicks in porpoise habitats. J Acoust Soc Am 127: 560-567. doi:10.1121/1.3257203.

Geelhoed SCV, Friedrich E, Joost M, Machiels MAM and Stöber N (2018) Gemini T-c: aerial surveys and passive acoustic monitoring of harbour porpoises 2015. Wageningen Marine Research report C020/17. doi.org/10.18174/410635

Harwood J, King S, Booth C, Donovan C, Schick RS, Thomas L and New L (2016) Understanding the population consequences of acoustic disturbance for marine mammals. In: The Effects of Noise on Aquatic Life II. Springer, pp: 417-423.

Kastelein RA, Hardeman J and Boer H (1997) Food consumption and body weight of harbour porpoises (Phocoena phocoena). In: AJ Read, PR Wiepkema, \& PE Nachtigall (Eds.), The biology of the harbour porpoise. Pp: 217-233. Woerden, The Netherlands: De Spil Publishers.

Kastelein RA (1998) Food consumption and growth of marine mammals, 647 pages. Wageningen University PhD Thesis.

Kastelein RA, Helder-Hoek , L Jennings N, van Kester R and Huisman R (2019) Reduction in Body Mass and Blubber Thickness of Harbor Porpoises (Phocoena phocoena) Due to Near-Fasting for 24 Hours in Four Seasons. Aquatic Mammals 45(1): 37-47.

Jansen OE, Michel L, Lepoint G, Das K, Couperus AS and Reijnders PJ (2013) Diet of harbor porpoises along the Dutch coast: A combined stable isotope and stomach contents approach. Mar Mam Sci 29: E295-E311. doi:10.1111/j.1748-7692.2012.00621.x

Leeney RH, Carslake D and Elwen SH (2011) Using Static Acoustic Monitoring to describe echolocation behaviour of Heaviside's dolphins in Namibia. Aquat Mamm 37: 151-160.

Leopold MF (2015) Eat or be eaten: porpoise diet studies, 239 pages. Wageningen University PhD Thesis.

Linnenschmidt M, Teilmann J, Akamatsu T, Dietz R and Miller LA (2013) Biosonar, dive and foraging activity of satellite tracked harbour porpoises (Phocoena phocoena). Mar Mamm Sci 29: E77-E97. doi:10.1111/j.1748-7692.2012.00592.x.

Miller LA (2010) Prey Capture by Harbor Porpoises (Phocoena phocoena): A Comparison Between Echolocators in the Field and in Captivity. J. Marine Acoust. Soc. Jpn. 37(3): 156-168. 
Nabe-Nielsen J, Sibly RM, Tougaard J, Teilmann J and Sveegaard S (2014) Effects of noise and by-catch on a Danish harbour porpoise population. Ecological Modelling 272: 242-251.

Nabe-Nielsen, J. \& Harwood, J. (2016). Comparison of the iPCoD and DEPONS models for modelling population consequences of noise on harbour porpoises. Aarhus University, DCE - Danish Centre for Environment and Energy, 22 pp. Scientific Report from DCE - Danish Centre for Environment and Energy No. 186. ISBN 9788771562057

Nabe-Nielsen, J., van Beest, F.M., Grimm, V., Sibly, R.M., Theilmann, J., Thompson, P.M. (2018). Predicting the impact of anthropogenic disturbances on marine populations. Conservation Letters, 11(5).Nurminem A (2010) Foraging and habitat use of harbour porpoise (Phocoena phocoena) in Cardigan Bay SAC: Effects of season, location and bottlenose dolphin (Tursiops truncatus) presence. University of Bangor MSC Thesis.

Pirotta E, Thompson PM, Miller PI, Brookes KL, Cheney B, Barton TR, Graham IM and Lusseau D (2014a) Scale-dependent foraging ecology of a marine top predator modelled using passive acoustic data. Functional Ecology 28(1): 206-217.

Pirotta E, Brookes KL, Graham IM and Thompson PM (2014b) Variation in harbour porpoise activity in response to seismic survey noise. Biology Letters 10(5): 20131090.

Pirotta, E., Booth, C. G., Costa, D. P., Fleishman, E., Kraus, S. D., Lusseau, D., ... Harwood, J. (2018). Understanding the population consequences of disturbance. Ecology and Evolution, 8(19), 99349946.

Simon M, Nuuttila H, Reyes-Zamudio MM, Ugarte F, Verfuss U and Evans PGH (2010) Passive acoustic monitoring of bottlenose dolphin and harbour porpoise, in Cardigan Bay, Wales, with implications for habitat use and partitioning. J Mar Biol Assoc UK 90(8): 1539-1545. doi: $10.1017 /$ S0025315409991226.

Sarnocinska J, Tougaard J, Johnson M, Madsen PT and Wahlberg M (2016) Comparing the performance of C-PODs and SoundTrap/PAMGUARD in detecting the acoustic activity of harbor porpoises (Phocoena phocoena). In: Proceedings of Meetings on Acoustics (p. 070013). https://doi.org/10.1121/2.0000288

Schaffeld T, Bräger S, Gallus A, Dähne M, Krügel K, Hermann A, Jabbusch M, Ruf T, Verfuß UK, Benke $\mathrm{H}$ and Koblitz JC (2016) Diel and seasonal patterns in acoustic presence and foraging behaviour of free-ranging harbour porpoises. Mar Ecol Prog Ser 547: 257-272. doi.org/10.3354/meps11627

Scheidat M, Tougaard J, Brasseur S, Carstensen J, Van Polanen-Petel T, Teilmann J and Reijnders P (2011) Harbour porpoises (Phocoena phocoena) and wind farms: a case study in the Dutch North Sea. Environ. Res. Lett. 6025102

Sørensen PM, Wisniewska DM, Jensen FH, Johnson M, Teilmann J and Madsen P (2018) Click communication in wild harbour porpoises (Phocoena phocoena). Scientific Reports Volume 8 , Article number: 9702. Available at: https://www.nature.com/articles/s41598-018-28022-8\#ref-CR29

Sostres Alonso M and Nuuttila HK (2015) Detection rates of wild harbour porpoises and bottlenose dolphins using static acoustic click loggers vary with depth. Bioacoustics 24 (2): 101-110. doi.org/10.1080/09524622.2014.980319

Todd VLG, Pearse WD, Tregenza NC, Lepper PA, and Todd IB (2009) Diel echolocation activity of harbour porpoises (Phocoena phocoena) around North Sea offshore gas installations. ICES Journal of Marine Science 66(4): 734-745. https://doi.org/10.1093/icesjms/fsp035

Urick RJ (1996) Principles of Underwater Sound 3rd Edition. Peninsula Pub.

Verboom WC and Kastelein RA (1995) Acoustic signals by harbour porpoises (Phocoena phocoena) 139 pp. In: Nachtigall PE, Lien J, Au WWL and Read AJ (eds), Harbour porpoises - Laboratory Studies to Reduce Bycatch. De Spil Publishers, Woerden, the Netherlands, $168 \mathrm{pp}$.

Verfuss UK, Miller LA, Pilz PKD and Schnitzler H-U (2009) Echolocation by two foraging harbour porpoises (Phocoena phocoena). The Journal of Experimental Biology 212: 823-834.

Villadsgaard A, Wahlberg M and Tougaard J, 2007. Echolocation signals of wild harbour porpoises, Phocoena phocoena. Journal of Experimental Biology 210(1): 56-64.

Wisniewska DM, Johnson M, Teilmann J, Rojano-Doñate L, Shearer J, Sveegaard S, Miller LA, Siebert U and Madsen PT (2016) Ultra-high foraging rates of harbor porpoises make them vulnerable to anthropogenic disturbance. Current Biology 26(11): 1441-1446.

Wisniewska DM, Johnson M, Teilmann J, Siebert U, Galatius A, Dietz R and Madsen PT (2018) High rates of vessel noise disrupt foraging in wild harbour porpoises (Phocoena phocoena). Proc Biol Sci. 2018 Feb 14: 285(1872). pii: 20172314. doi: 10.1098/rspb.2017.2314. 


\section{Annex I: additional results}

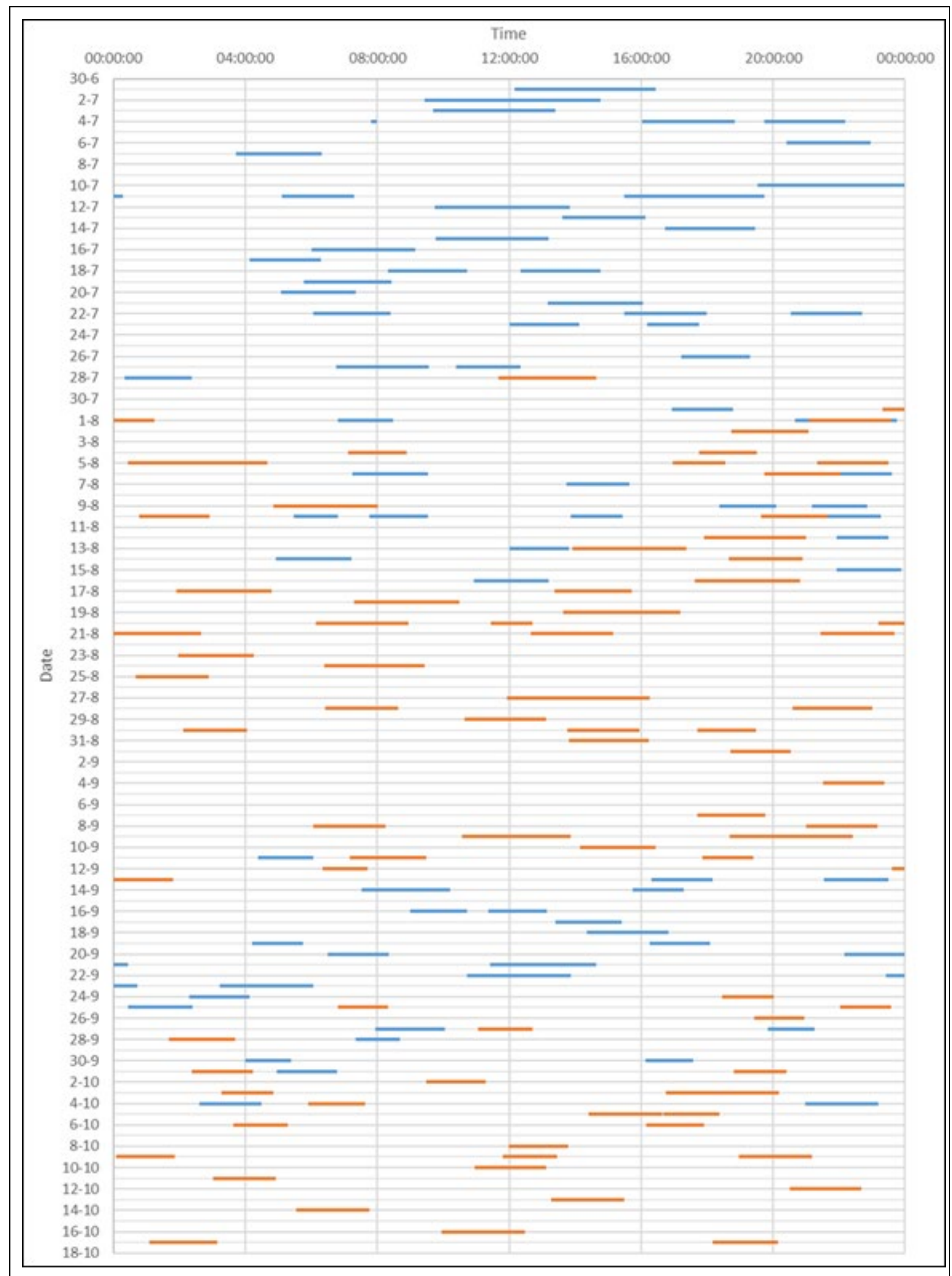

Figure I.1: Timing of pile driving activity in ZeeEnergie (orange) and Buitengaats (blue), 1 July - 17 October 2015. Bars show timing and duration of pile driving (see Annex 2 for details). 


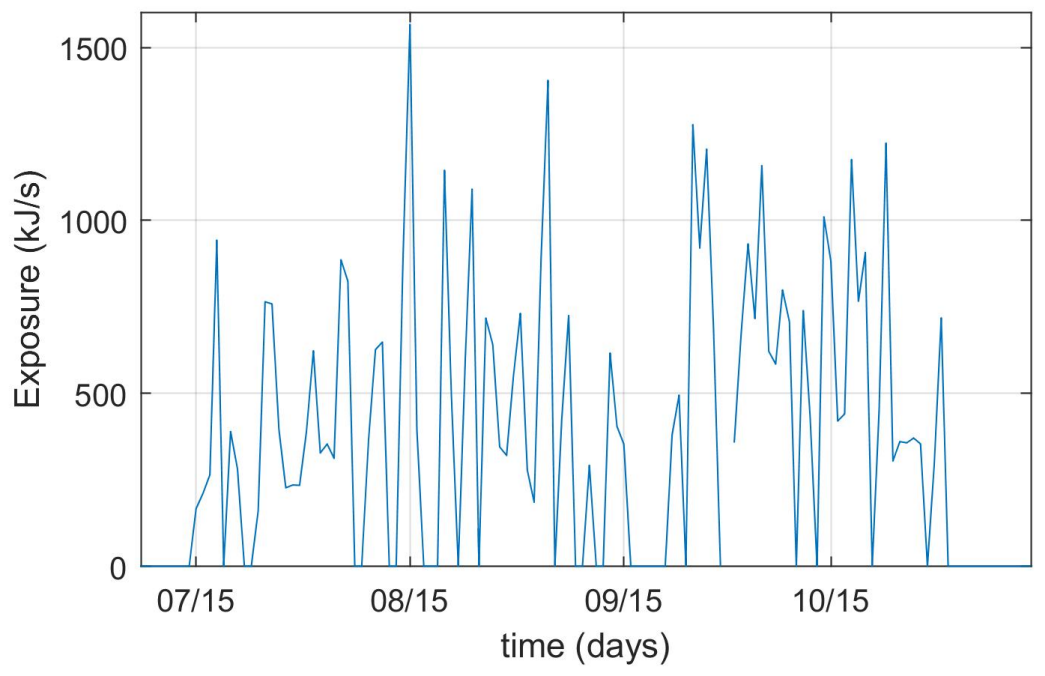

Figure I.2: pile driving activity (as rate of energy in $\mathrm{kJ} / \mathrm{s}$ ) for each day of exposure.
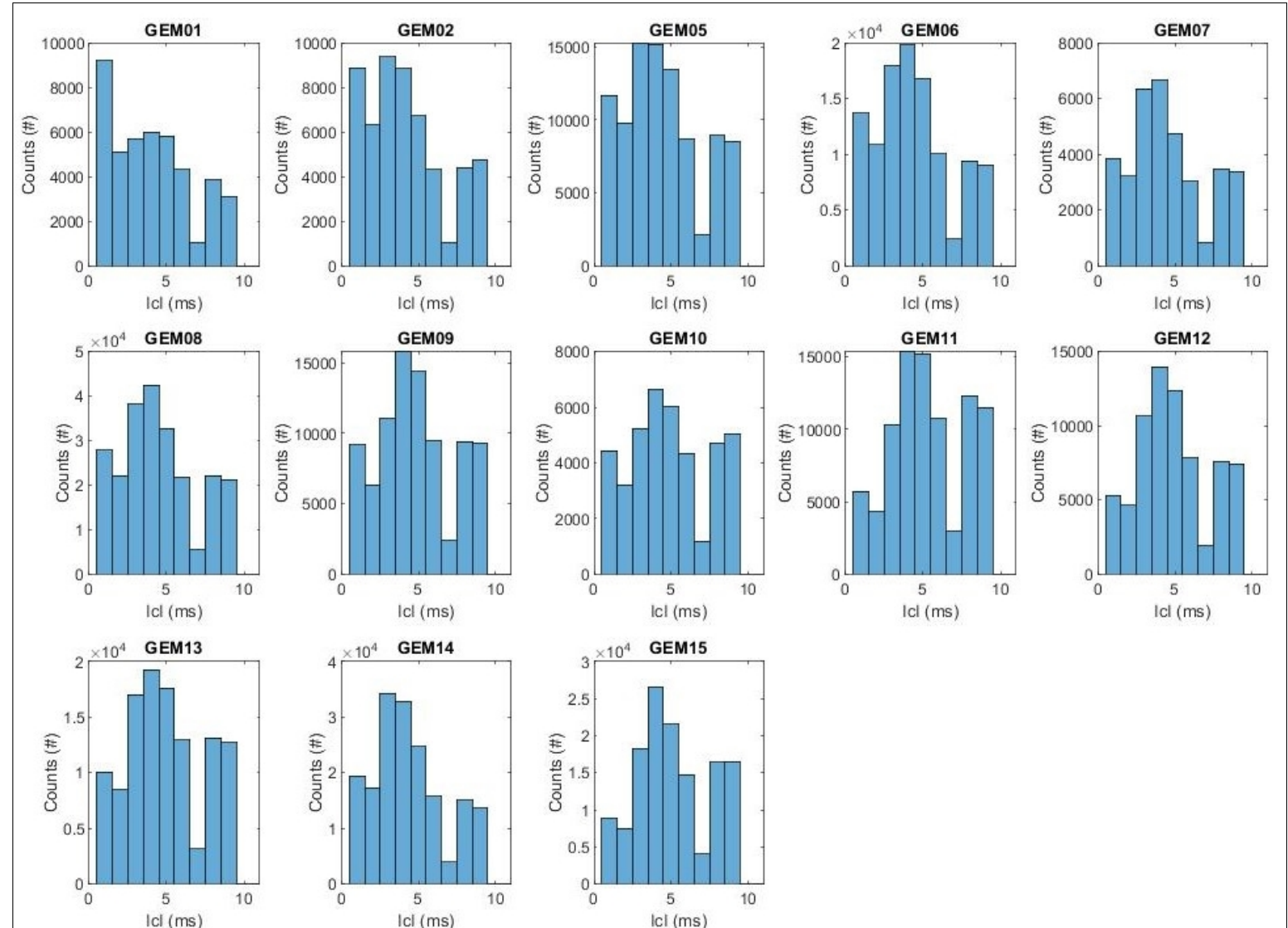

Figure I.3: Distribution of detected ICIs using the Pirotta et al. (2014) method (Section 3.2) for all CPOD stations (Figure 2 and Table 1). 

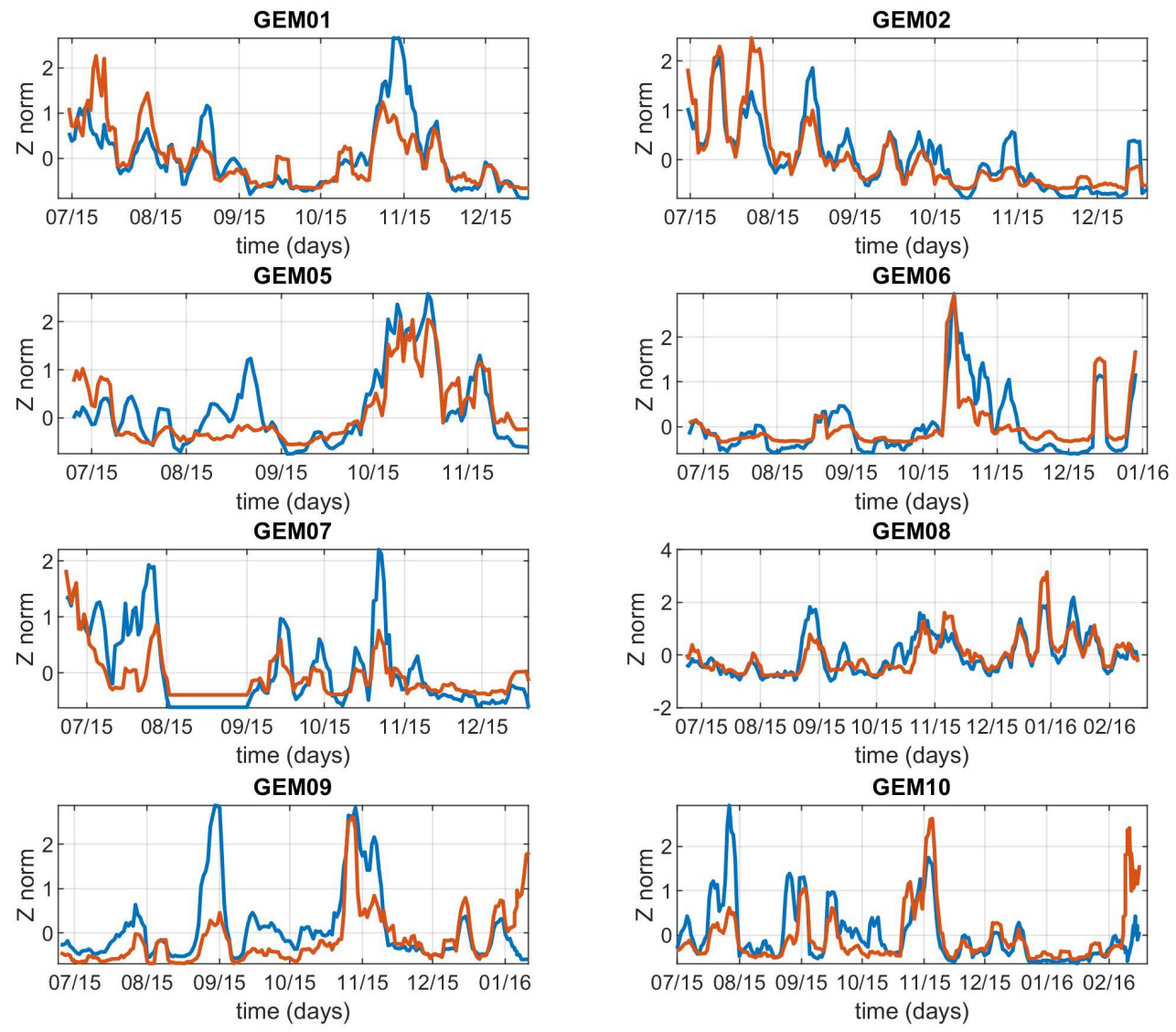

$07 / 15$ 08/15 09/15 10/15 11/15 12/15 01/16 02/16 time (days)

GEM11

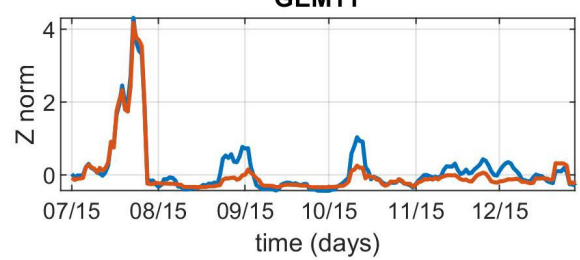

GEM12

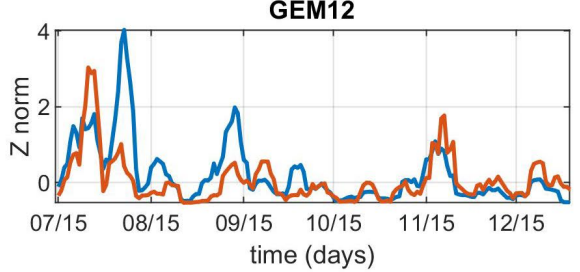

GEM14
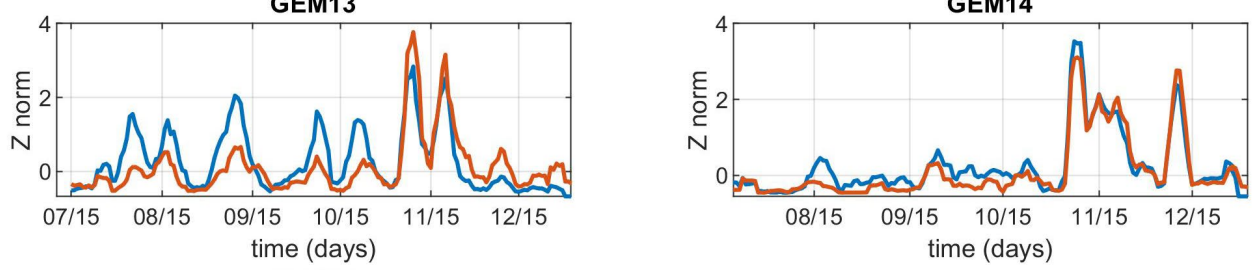

GEM15

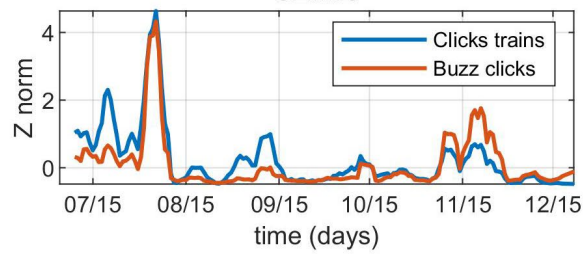

Figure I.4: Comparison of the number of click trains and buzz clicks per day for all CPOD stations. Click trains are those regrouped using a 1 second separation threshold (Section 3.1, solid blue line). Buzz clicks are determined using the click based method described in Section 3.2. Both time series are $Z$ normalized for comparison. In addition, a 5 days rolling average is applied to smooth the signal and retain long term trends. 

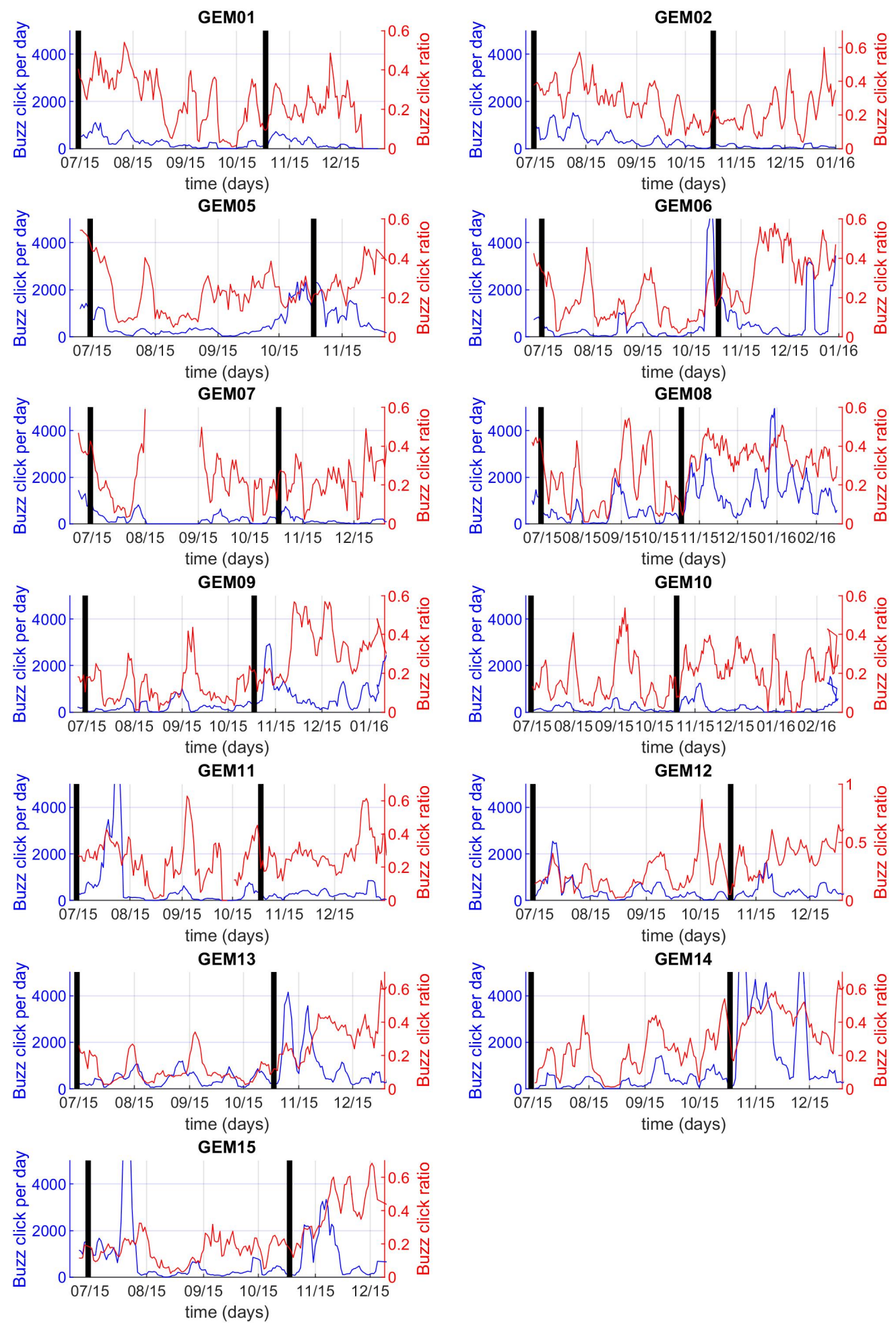

Figure I.5: Buzz clicks per day and corresponding buzz ratio for all CPOD stations. A rolling average of 5 days is applied to the time series in order to reveal long term trends. The buzz click ratios are computed as in Equation (2) and is indicative of behavioural change. The vertical black lines indicate start and end of piling noise activities. The comparison with exposure level (i.e. relative to level pile driving and location) for each CPOD station is given in figures 15 and in Appendix I (Figure I.6 for buzz clicks per day and Figure I.7 for buzz click ratio). 

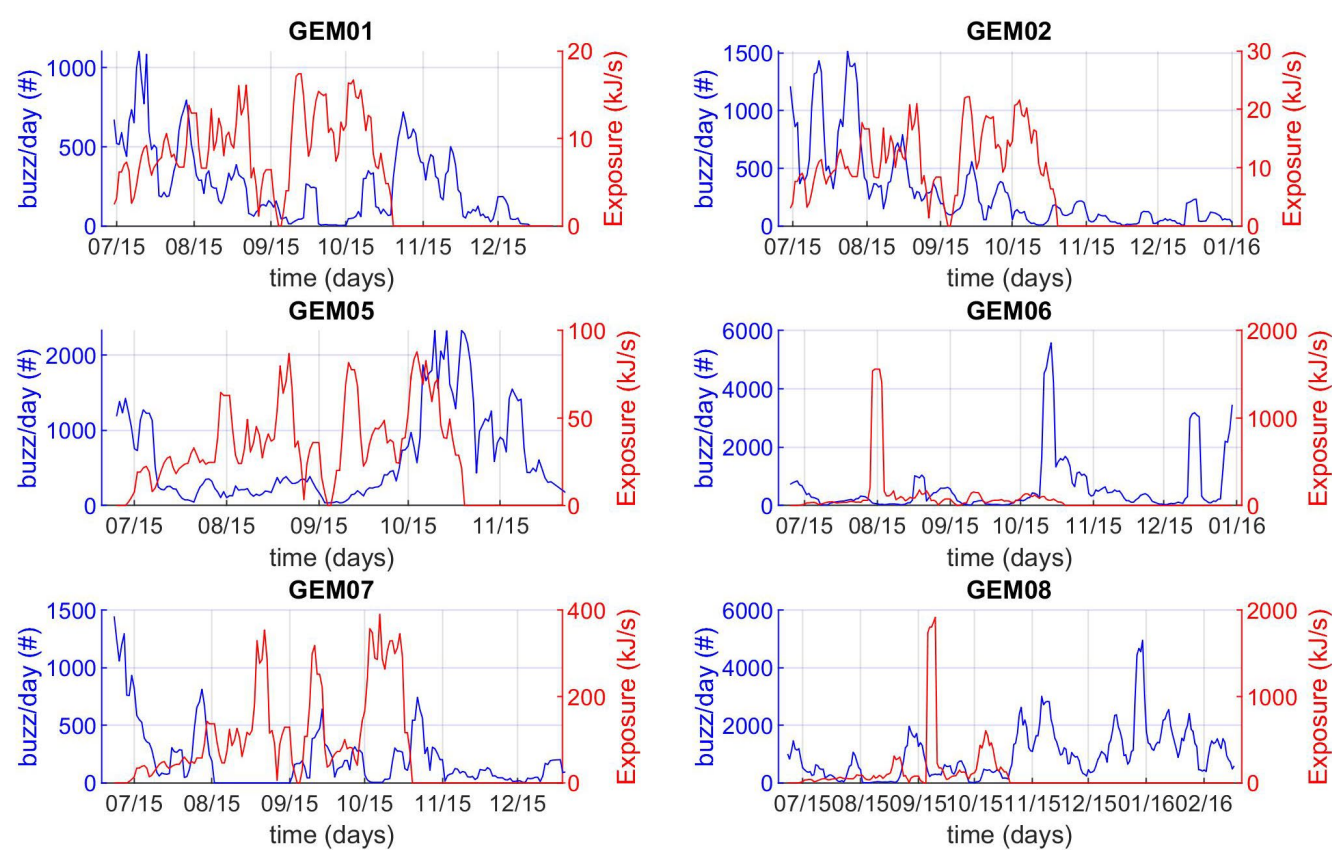

GEM08

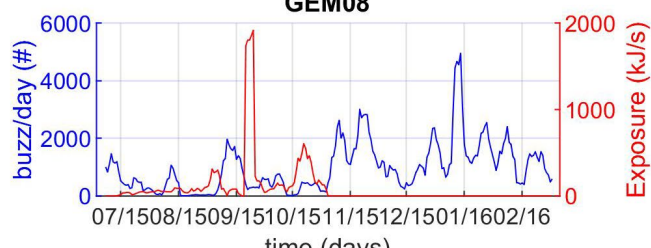
time (days)
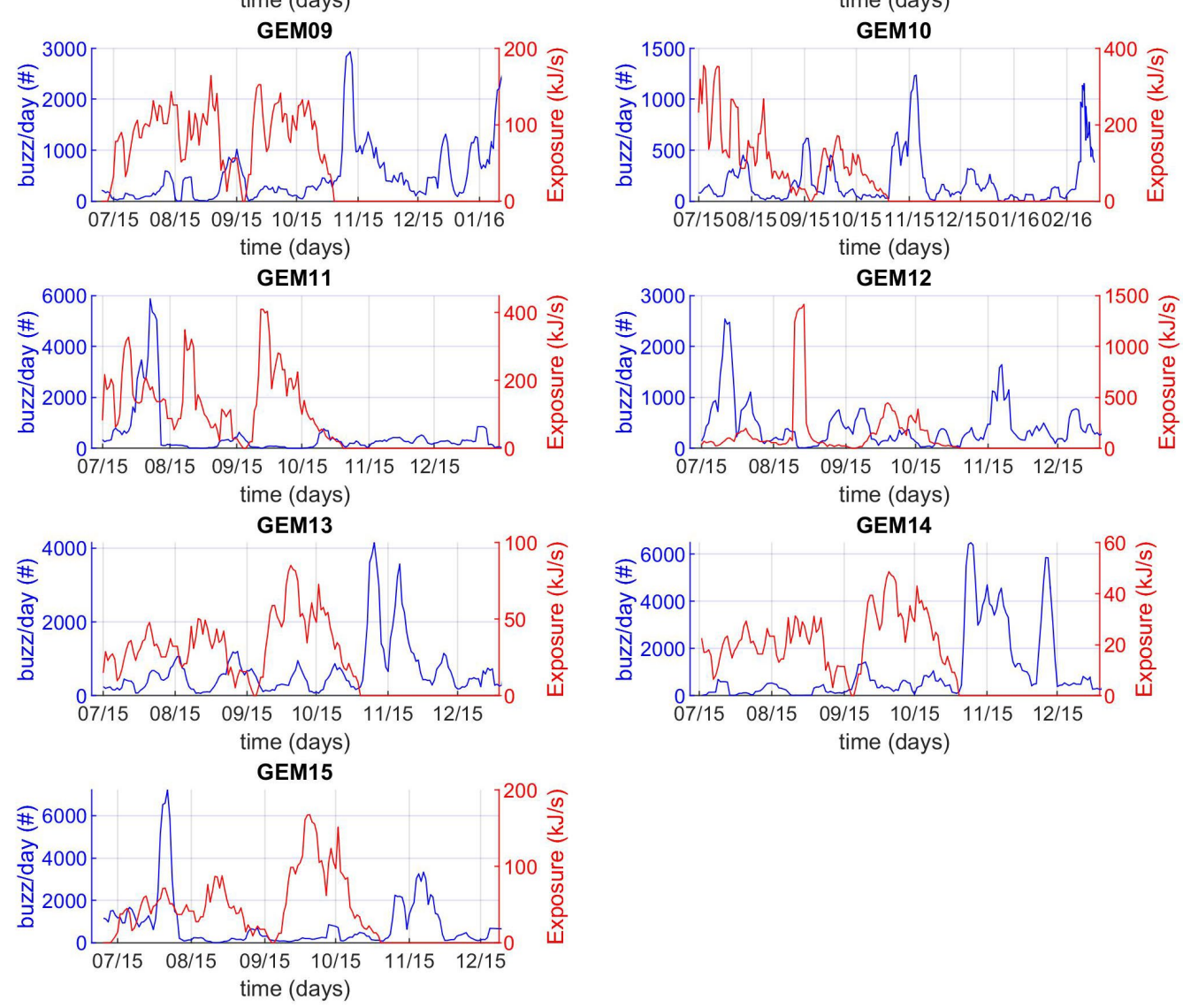

Figure I.6: variation of buzz clicks per day(solid blue line) and pile driving activity (solid red line) for all CPOD stations. The buzz click ratio is computed as in Equation (2) and is indicative of behavioural change. A rolling average of 5 days is applied to the time series in order to reveal long term trends. 
GEM01

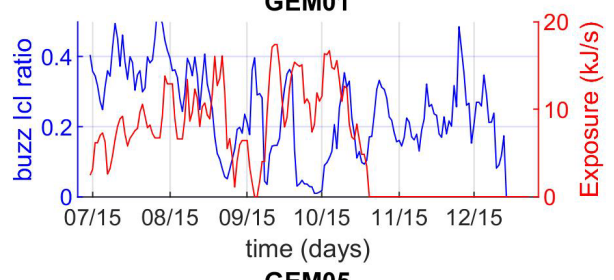

GEM05

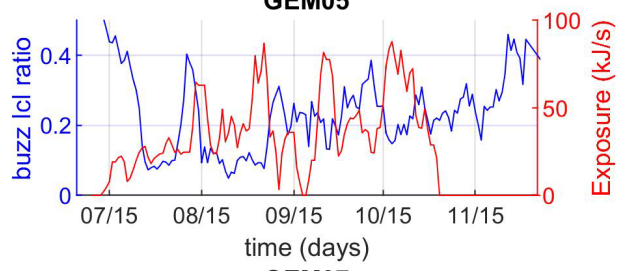

GEM07

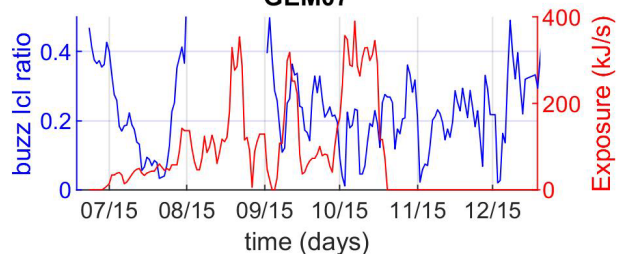

GEM09

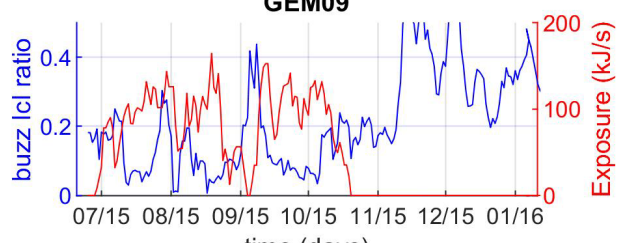

time (days)

GEM11

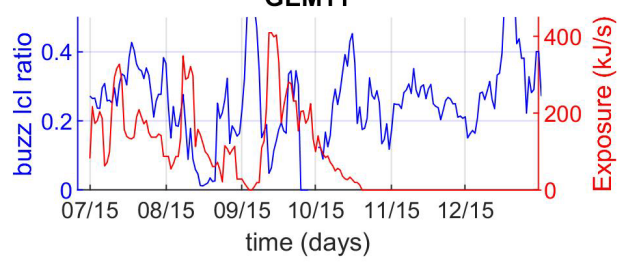

GEM13

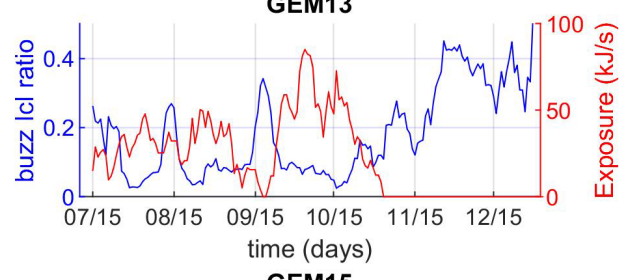

GEM15

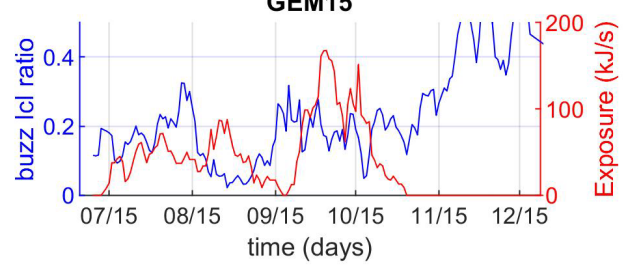

GEM02

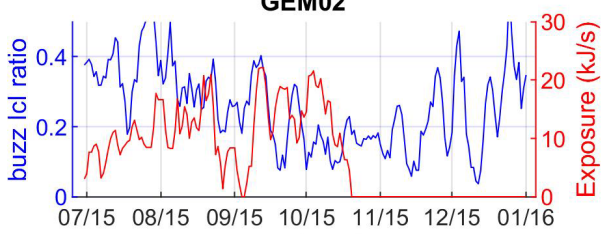
time (days)

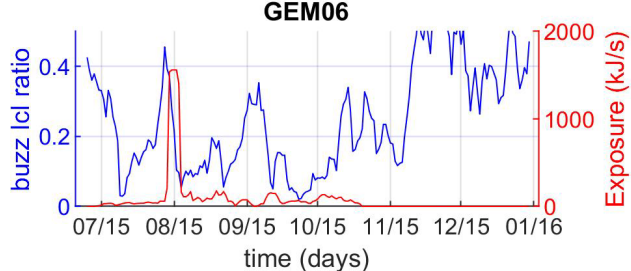

GEM08
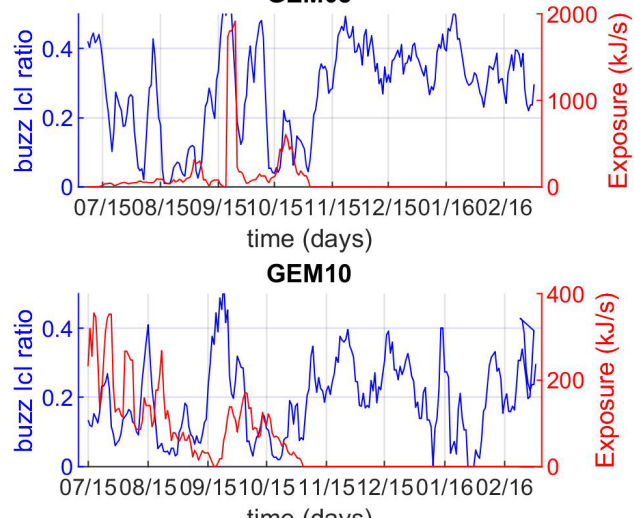

time (days)

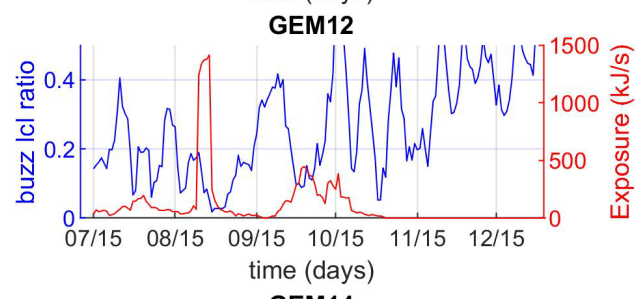

GEM14

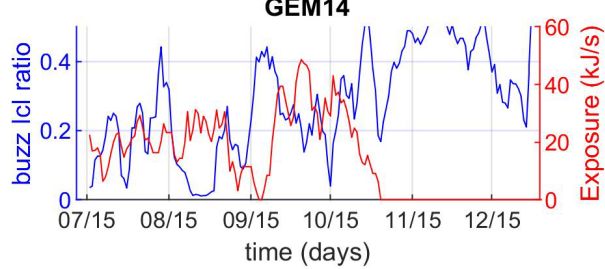

Figure I.7: Variation of buzz click ratio (solid blue line) and pile driving activity (solid red line) for all CPOD stations. The buzz click ratio is computed as in Equation (2) and is indicative of behavioural change. A rolling average of 5 days is applied to the time series in order to reveal long term trends. 

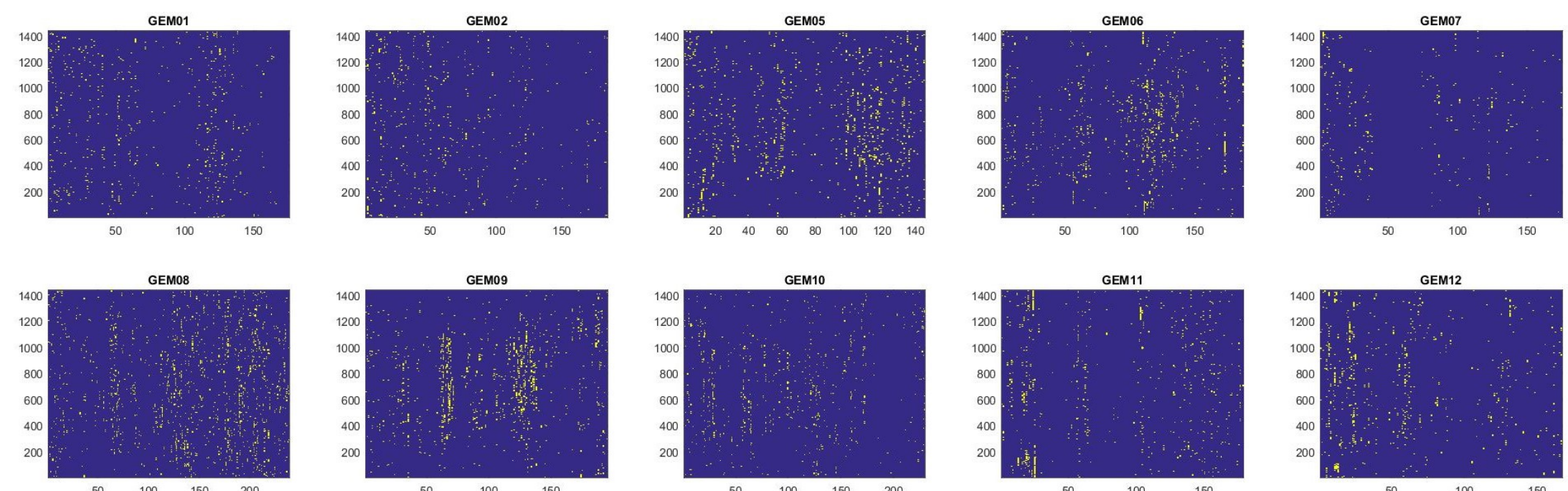

GEMO9

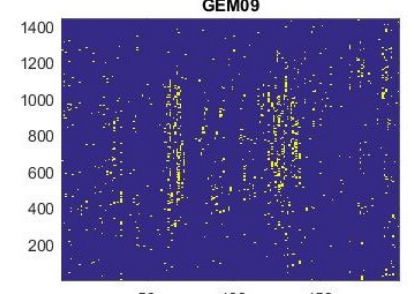

GEM10
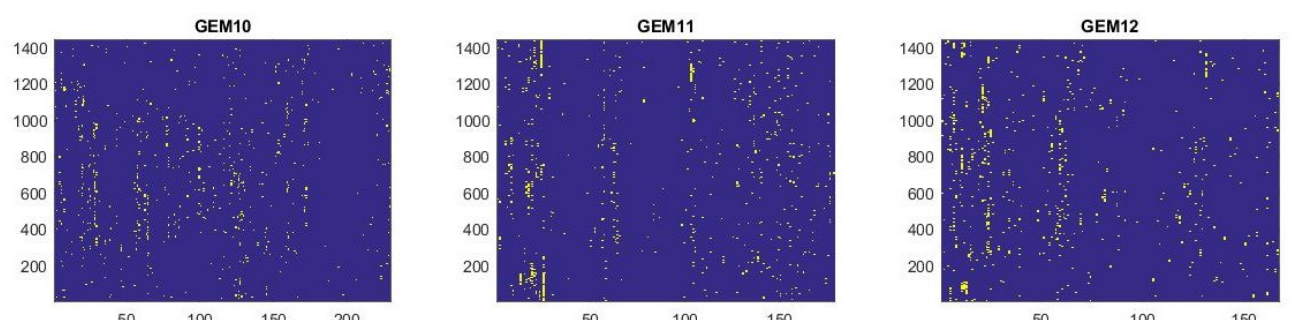

GEM13
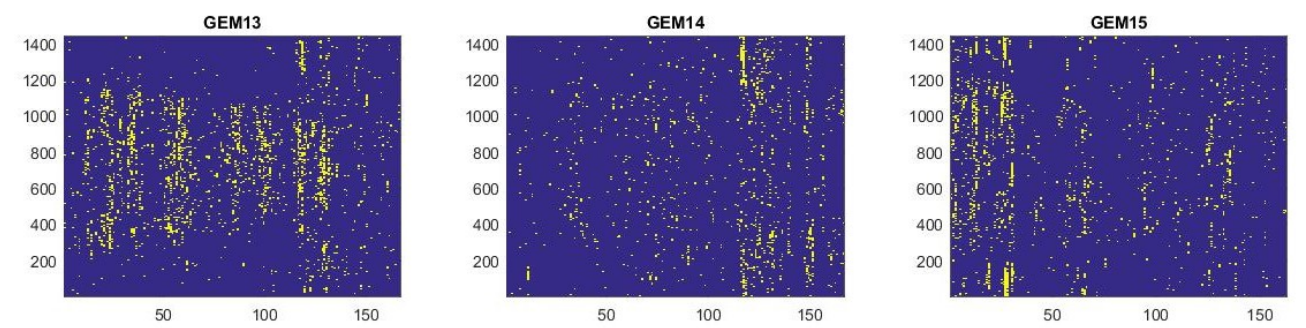

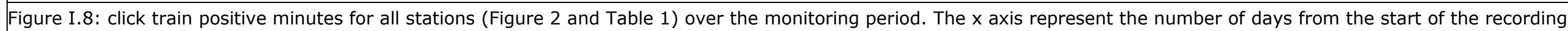

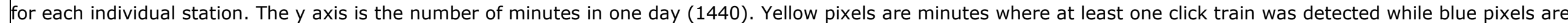
minutes where no click trains are detected. 


\section{Justification}

Report C039/19

Project Number: 4316100147

The scientific quality of this report has been peer reviewed by a colleague scientist and a member of the Management Team of Wageningen Marine Research

Approved: $\quad$ Bart Noort

Researcher

Signature:

Date: 21 June 2019

Approved: Drs. J. Asjes

Member MT

Signature:

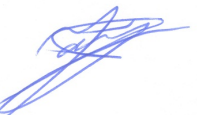

Date: 21 June 2019 
Wageningen Marine Research

$\mathrm{T}+31(0) 317480900$

E: marine-research@wur.nl

www.wur.eu/marine-research

Visitors' address

- Ankerpark 271781 AG Den Helder

- Korringaweg 7, 4401 NT Yerseke

- Haringkade 1, 1976 CP IJmuiden
Wageningen Marine Research is the Netherlands research institute established to provide the scientific support that is essential for developing policies and innovation in respect of the marine environment, fishery activities, aquaculture and the maritime sector.

\section{Wageningen University \& Research:}

is specialised in the domain of healthy food and living environment.

\section{The Wageningen Marine Research vision}

'To explore the potential of marine nature to improve the quality of life'

\section{The Wageningen Marine Research mission}

- To conduct research with the aim of acquiring knowledge and offering advice on the sustainable management and use of marine and coastal areas.

- Wageningen Marine Research is an independent, leading scientific research institute

Wageningen Marine Research is part of the international knowledge organisation Wageningen UR (University \& Research centre). Within Wageningen UR, nine specialised research institutes of the Stichting Wageningen Research Foundation have joined forces with Wageningen University to help answer the most important questions in the domain of healthy food and living environment. 